\title{
Implications of ethylene biosynthesis and signaling in soybean drought stress tolerance
}

Fabricio Barbosa Monteiro Arraes ${ }^{1,2}$, Magda Aparecida Beneventi ${ }^{1,2}$, Maria Eugenia Lisei de Sa ${ }^{2,4}$, Joaquin Felipe Roca Paixao ${ }^{2,3}$, Erika Valeria Saliba Albuquerque ${ }^{2}$, Silvana Regina Rockenbach Marin ${ }^{5}$, Eduardo Purgatto ${ }^{6}$, Alexandre Lima Nepomuceno ${ }^{5}$ and Maria Fatima Grossi-de-Sa ${ }^{2,7^{*}}$

\begin{abstract}
Background: Ethylene is a phytohormone known for inducing a triple response in seedlings, leaf abscission and other responses to various stresses. Several studies in model plants have evaluated the importance of this hormone in crosstalk signaling with different metabolic pathways, in addition to responses to biotic stresses. However, the mechanism of action in plants of agricultural interest, such as soybean, and its participation in abiotic stresses remain unclear.

Results: The studies presented in this work allowed for the identification of 176 soybean genes described elsewhere for ethylene biosynthesis (108 genes) and signal transduction (68 genes). A model to predict these routes in soybean was proposed, and it had great representability compared to those described for Arabidopsis thaliana and Oryza sativa. Furthermore, analysis of putative gene promoters from soybean gene orthologs permitted the identification of 29 families of cis-acting elements. These elements are essential for ethylenemediated regulation and its possible crosstalk with other signaling pathways mediated by other plant hormones. From genes that are differentially expressed in the transcriptome database, we analyzed the relative expression of some selected genes in resistant and tolerant soybean plants subjected to water deficit. The differential expression of a set of five soybean ethylene-related genes (MAT, ACS, ACO, ETR and CTR) was validated with RT-qPCR experiments, which confirmed variations in the expression of these soybean target genes, as identified in the transcriptome database. In particular, two families of ethylene biosynthesis genes (ACS and ACO) were upregulated under these experimental conditions, whereas CTR (involved in ethylene signal transduction) was downregulated. In the same samples, high levels of ethylene production were detected and were directly correlated with the free fraction levels of ethylene's precursor. Thus, the combination of these data indicated the involvement of ethylene biosynthesis and signaling in soybean responses to water stress.

(Continued on next page)
\end{abstract}

\footnotetext{
* Correspondence: fatima.grossi@embrapa.br

${ }^{2}$ Embrapa Genetic Resources and Biotechnology, PqEB, Av. W5-Norte, Postal

Code 02372, CEP 70770-910, Brasilia, DF, Brazil

${ }^{7}$ Catholic University of Brasilia, SGAN 916, Modulo B, Av. W5, Asa Norte, CEP

70790-160, Brasilia, DF, Brazil

Full list of author information is available at the end of the article
}

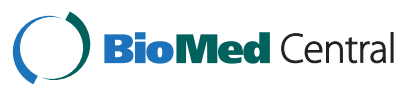

(c) 2015 Arraes et al. Open Access This article is distributed under the terms of the Creative Commons Attribution 4.0 International License (http://creativecommons.org/licenses/by/4.0/), which permits unrestricted use, distribution, and reproduction in any medium, provided you give appropriate credit to the original author(s) and the source, provide a link to the Creative Commons license, and indicate if changes were made. The Creative Commons Public Domain Dedication waiver (http://creativecommons.org/publicdomain/zero/1.0/) applies to the data made available in this article, unless otherwise stated. 
(Continued from previous page)

Conclusions: The in silico analysis, combined with the quantification of ethylene production (and its precursor) and RT-gPCR experiments, allowed for a better understanding of the importance of ethylene at a molecular level in this crop as well as its role in the response to abiotic stresses. In summary, all of the data presented here suggested that soybean responses to water stress could be regulated by a crosstalk network among different signaling pathways, which might involve various phytohormones, such as auxins, ABA and jasmonic acid. The integration of in silico and physiological data could also contribute to the application of biotechnological strategies to the development of improved cultivars with regard to different stresses, such as the isolation of stress-specific plant promoters.

\section{Background}

Phytohormones are organic compounds that exist naturally in plants and that even in low concentrations, orchestrate a broad range of physiological processes, including growth and development, as well as responses to abiotic and biotic stresses [1]. These hormones overlap signal transduction pathways or gene expression profiles by rapid induction or by preventing the degradation of transcriptional regulators [2-5].

Among all of the described phytohormones, ethylene, a naturally occurring triple response growth regulator (shoot elongation, stem thickening and horizontal growth habit) in seedlings, has been studied since ancient times [6]. Ethylene is also involved in leaf abscission, fruit ripening and senescence $[6,7]$ as well as seed germination, growth of adventitious roots under flooding conditions, epinasty stimulation, inhibition of shoot growth and stomatal closing and flowering $[8,9]$. Moreover, it is involved in a wide variety of stresses, including wounding, pathogen attack, flooding, drought, hypoxia, and temperature shifts $[10,11]$.

Ethylene biosynthesis is derived from the amino acid methionine provided by the Yang cycle [12], in which the precursor S-adenosylmethionine (AdoMet or SAM) is synthesized from ATP and methionine by S-adenosylmethionine synthetase (SAMS; EC 2.5.1.6) [13]. AdoMet is then converted into 1-aminocyclopropane-1carboxylic acid (ACC) and 5-methylthioadenosine (MTA) by the enzyme 1-aminocyclopropane-1-carboxylase synthase (ACS, EC 4.4.1.14) [13]. MTA is recycled through a series of Yang cycle reactions back to methionine [14].

Active ACSs are encoded by eight genes in Arabidopsis thaliana, and at least one encodes a catalytically inactive ACS (AtACS1) [15-17]. Based on the sequence present in its C-terminal region, these proteins can be divided into three main groups: type I proteins, which are the targets for phosphorylation by mitogen-activated protein kinase 3 and/or 6 (AtMPK3-6; EC 2.7.11.24) [18] as well as by calcium-dependent protein kinase (AtCDPK2; CDPK or CPK; EC 2.7.11.1); type II proteins, which show phosphorylation sites for only CPK [19]; and type III proteins, which have the $\mathrm{C}$-terminal portion greatly reduced and do not present phosphorylation sites for either kinase. Furthermore, the ACSs can be regulated by putative endogenous signal receptors (i.e., phytohormones) and/or intracellular accumulation of secondary metabolites, such as calcium. In the absence of an endogen signal, type II ACSs are degraded by $26 \mathrm{~S}$ proteasome. This degradation is mediated by ETO proteins (ethylene overproducer) and EOL (ETO-like), which are members of specific plant proteins with E3 ubiquitin ligase domain [20]. This process activates kinase protein signaling, which culminates in the stabilization of type II ACSs. Furthermore, MPK3-6 kinases are able to phosphorylate the C-terminal of type I ACSs, which preserve and stabilize their degradation via the $26 \mathrm{~S}$ proteasome pathway, thereby increasing the production of ethylene and inducing other ethylene-dependent signaling pathways [21].

The enzyme directly responsible for the ethylene biosynthesis is 1-aminociclopropane-1-acid carboxylic oxidase (ACO or EFE - ethylene forming enzyme; EC 1.14.17.4), which converts ACC into this plant hormone [22].

Several reports have suggested that the ACC metabolite could combine with other organic molecules. Different studies have demonstrated that the ACC N-malonyzation pathway in various plant tissues is involved in the regulation of ethylene production, wherein the conjugate 1malonyl-ACC (MACC) is formed by 1-aminocyclopropane1-acid carboxylic acid-N-malonyltransferase, an enzyme that has been purified from plant protein extracts but without reference to its respective gene $[23,24]$. In addition to MACC formation through a metabolic route, ACC can also be conjugated in the form of 1-glutamyl-ACC (GACC) in a reaction that is catalyzed by $\gamma$-glutamyl transpeptidase (GGT; EC 2.3.2.2) [25].

Another possible ACC metabolic pathway is the reaction catalyzed by the enzyme ACC deaminase (ACD; EC 3.5.99.7), a protein that degrades ACC into oxobutyrate (or OXB; 2-oxobutanoate) and ammonia $\left(\mathrm{NH}_{3}\right)$, thus decreasing the levels of ACC that are available for ethylene production [26, 27]. The $A C D$ gene was first identified in A. thaliana and Populus, and studies of tomato plants have shown that ACD activity varies during fruit ripening and that its peak activity coincides with the reduction in ethylene synthesis [28, 29]. 
The classic routes of ethylene intracellular signal transduction, initially described in A. thaliana, are triggered by the gas interaction with membrane receptors (encoded by ETR genes - ethylene receptor) and the modulation of CTR1 (constitutive triple response - MKKK; EC 2.7.11.1) activity to regulate the expression of several genes, such as EIN3/EIL (ethylene insensitive 3; EIN3-like). Both receptors and CTR1 function as negative regulators of the signal transduction pathway in the absence of ethylene. The kinase CTR1 phosphorylates the EIN2 (ethylene insensitive 2) C-terminal domain, allowing for the degradation of this protein. ETP1 and ETP2 (EIN2 targeting protein) play important roles in EIN2 proteolysis. These proteins, which have F-box domains, interact with the conserved EIN2 C-terminal domain that was previously phosphorylated by CTR1. Thus, in the absence of ethylene, the phosphorylated EIN2 C-terminal domain is ubiquitinated and then degraded by the $26 \mathrm{~S}$ proteasome [30]. However, in the presence of ethylene, instead of being phosphorylated, the EIN2 domain is cleaved and transported to the nucleus to stimulate EIN3/EIL activity by repressing EBF (EIN3 binding F-box protein). Thus, EIN3/EINL induce the transcription of target genes, mainly the AP2/ERF transcription factor superfamily [31]. Earlier studies have also suggested an EIN3/EIL activation route independent of EIN2 and CTR via a phosphorylation cascade of kinase proteins, MKK4-5-9 (EC 2.7.12.2) $\rightarrow$ MPK3-6, which is mitogen activated $[21,32,33]$. In the presence of a signal, EIN3/EIL transcription factors are phosphorylated by MPK3-6 and do not interact with the F-box protein EBF (EIN3 binding F-box protein), preventing their degradation through the $26 \mathrm{~S}$ proteasome. Thus, these factors that accumulate in the nucleus interact with target gene promoters and trigger different ethylene responses [33]. In addition, the exoribonuclease 5'-3' EIN5 (EC 3.1.1.3.-), another positive regulator, promotes EBF mRNA decrease and thereby increases EIN3/EIL protein levels in the nucleus [34].

Ethylene signal transduction triggers substantial changes in the gene expression of plant cells. Promoter region analyses of the genes induced by ethylene led to the identification of cis-acting elements as well as the trans-acting protein EREBP (ethylene responsive element binding protein) family, which interacts with DNA and ERFs (ethylene response factors) [35-37]. Recent studies have demonstrated that EIN3/EIL are ERF1 (ethylene response factor 1) gene activators, constituting an ERF family member that establishes a hierarchy of ethylene-mediated signaling [38]. The homodimers EIN3/EIL interact with cis-acting elements in the ERF1 promoter region that once transcribed and translated, interact with other cis-acting elements present in the promoter regions of target genes [38]. EIN3 can induce transcription not only of ERF1 but also of other members of the AP2/ERF transcription factor superfamily [39].
The mechanism underlying environmental stress tolerance has been extensively studied in model plants in attempts to determine its impact on agriculture [40]. The metabolic pathways induced under drought in A. thaliana have been associated with abscisic acid (ABA)-dependent and ABA-independent pathways governing droughtinducible gene expression $[41,42]$ as well as the existence of an interconnection between both signaling pathways $[43,44]$. Furthermore, advanced ABA and ethylene signaling research has revealed that under stress, both hormones act antagonistically among yield-impacting processes [45].

Although ethylene has been extensively studied in the plant senescence process, its role during droughtinduced senescence is less well known. It has been demonstrated that under drought conditions, ethylene caused leaf abscission and consequently reduced water loss [46]. Under water deficit, ethylene production was paralleled by an increase and subsequent decrease in ACC, suggesting that water stress induced the de novo synthesis of ACC synthase, which is the rate-controlling enzyme along the pathway of ethylene biosynthesis. Moreover, ethylene and its metabolic process are important for activating plant responses to flooding and water deficit [47, 48]. It activates a signal transduction network that culminates in the synthesis of several transcription factors that regulate gene activation/repression during stress, such as ERF1 [41, 49, 50].

Despite important insights having been reported in ethylene signaling pathways, the available studies have not addressed the soybean (Glycine $\max$ [L.] Merrill), an economically important crop. This commodity is the second largest source of edible oil and the most important highquality vegetable protein for feeding both humans and animals worldwide. However, deficiency in water supply can negatively impact this crop, reducing yields and posing threats to farmers and food production in several countries $[51,52]$.

Considering the important position that soybean occupies in the Brazilian economy, the second largest world soybean producer, the Brazilian Soybean Genome Consortium (GENOSOJA) was created to identify the genes related to different biotic and abiotic stresses. Because there have been no reports concerning ethylene molecular mechanisms in soybean, this work described the ethylene metabolic pathway in silico in the soybean genome using various databases. The gene expression profile data obtained from the GENOSOJA database was validated by RT-qPCR experiments, and determinations of free ACC levels and ethylene production in susceptible and tolerant soybean genotypes under water deficit conditions were also performed. Moreover, transcriptional regulation was studied by analyzing putative cis-acting elements present in the possible promoters. These data allowed for the inference of the first accurate in silico models for soybean 
Table 1 Ethylene biosynthesis and signal transduction gene summary in different plants

\begin{tabular}{llll}
\hline Group & Number of genes & \\
\cline { 2 - 4 } & Arabidopsis thaliana & Glycine max & Oryza sativa \\
\hline Biosynthesis & 44 & 108 & 38 \\
Signal Transduction & 30 & 68 & 34 \\
Total & 74 & 176 & 72 \\
\hline
\end{tabular}

ethylene biosynthesis and signaling, which facilitated a better understanding of the molecular mechanisms involved in this important phytohormone.

\section{Results and discussion In silico reconstruction of soybean ethylene molecular models}

To evaluate the influence of ethylene in soybean water stress response, it was necessary to reconstruct the metabolic pathways to improve those available in public databases. Hence, we conducted an extensive search in the crop genome for genes previously associated with ethylene biosynthesis and signal transduction. Thus, a total of 322 genes were analyzed, of which 146 corresponded to model plants (74 from Arabidopsis thaliana and 72 from Oryza sativa) and 176 to Glycine max (Table 1). All of the soybean genes were mapped on their respective chromosomes (Additional file 1: Figure S1) and were functionally annotated (Additional file 1: Figure S2). The proteins identified in model plants $A$. thaliana (Additional file 2: Table S1 and S2) and O. sativa (Additional file 2: Table S3 and S4) as well as in Glycine max (Additional file 2: Table S5 and S6) were thoroughly characterized in silico, making possible the identification of the main characteristic domains. The soybean orthologous proteins in A. thaliana and O. sativa were investigated by $\mathrm{BBH}$ (best bidirectional hit) analysis, comparing the three species databases (Additional file 1: Figure S3; Additional file 2: Table S7 and S8). According to these data (see Additional file 3), accurate soybean models of ethylene biosynthesis and signal transduction have been proposed.

The putative soybean proteins that participate in the metabolic pathways involved in ethylene biosynthesis and signaling mediated by this molecule are highly conserved, with domains that have already been described for their homologs in model organisms. The $\mathrm{BBH}$ experiment suggested a higher phylogenetic proximity of soybean to $A$. thaliana, corroborating that both are classified as dicotyledonous, although significant portions of these proteins are conserved in all three species. The ontological analysis indicated the same conclusion, showing that both function and molecular processes as well as the cell localization of these proteins were similar in different species.

\section{Soybean ethylene biosynthesis model}

Based on the model for ethylene biosynthesis in A. thali$a n a$, the 108 genes of soybean related to this metabolic route were divided into three groups: Yang cycle genes (21.3\%); ethylene biosynthesis (44.4\%); and ACC conjugation or degradation (34.3\%) (Additional file 2: Table S5).

Pommerrenig et al. [53] described a model for methionine recycling reactions through the Yang cycle in Plantago and A. thaliana [53]. Based on this work, we proposed an in silico model for this route in soybean, in which the homologs for all components were identified: MTN (5-methylthioadenosine nucleosidase; EC 3.2.2.16), MTK (5-methylthioribose kinase; EC 2.7.1.100), MTI (5methylthioribose-1-phosphate isomerase; EC 5.3.1.23), DEP (dehydratase-enolase-phosphatase complex; EC 4.2.1.109 and 3.1.3.77), ARD (acireductone dioxigenase; EC 1.13.11.53 and 1.13.11.54) and AAT (amino acid transferase) or ASP (aspartate aminotransferase) (EC 2.6.1.1) (Fig. 1). Each of the identified enzymes had at least one ortholog in A. thaliana and/or O. sativa identified in silico through the $\mathrm{BHH}$ experiment, suggesting plausible conservation of the pathway in different plant species.

The first enzyme in the biosynthesis pathway, MAT (methionine adenosyltransferase) or SAMS, is responsible for the production of the AdoMet used for ethylene production and also for lignin and polyamine synthesis [10, 54]. Among the eleven MAT proteins in soybean, five were $\mathrm{BHH}$ positive with possible orthologs in A thaliana and/or $O$. sativa.

Subsequently, the classification of 21 soybean ACSs was proposed by Tucker et al. [55], who reported phylogenetic relationships with similar ACSs in A. thaliana, suggesting that they are expressed when the plant is infected by the nematode Heterodera glycines [55]. In our work, we studied the phylogenetic relationships of ACS amino acids residues between G. $\max$ and A. thaliana and also with its homologues in O. sativa. We also determined in silico the possible phosphorylation sites of the respective kinases (Additional file 1: Figure S4). The distribution of the sequences is similar to that presented by Tucker [55] because they are distributed uniformly, indicating high conservation between species. Moreover, although the sequences of GmACS\#003, GmACS\#013, GmACS\#016 and GmACS\#019 present high similarity with ACS, they are phylogenetically unrelated to the rest because differences were found in the catalytic domain. Therefore, these sequences were named ACS-like, i.e., belonging to the family of AATs (amino acid transferases). Among the seventeen ACS sequences identified in soybean, six were possible orthologs of $A$. thaliana and/or $O$. sativa, of which two were determined to be type I (GmACS\#011 and GmACS\#014), two to be type II (GmACS\#017 and GmACS\#020) and two to be type III (GmACS\#006 and 


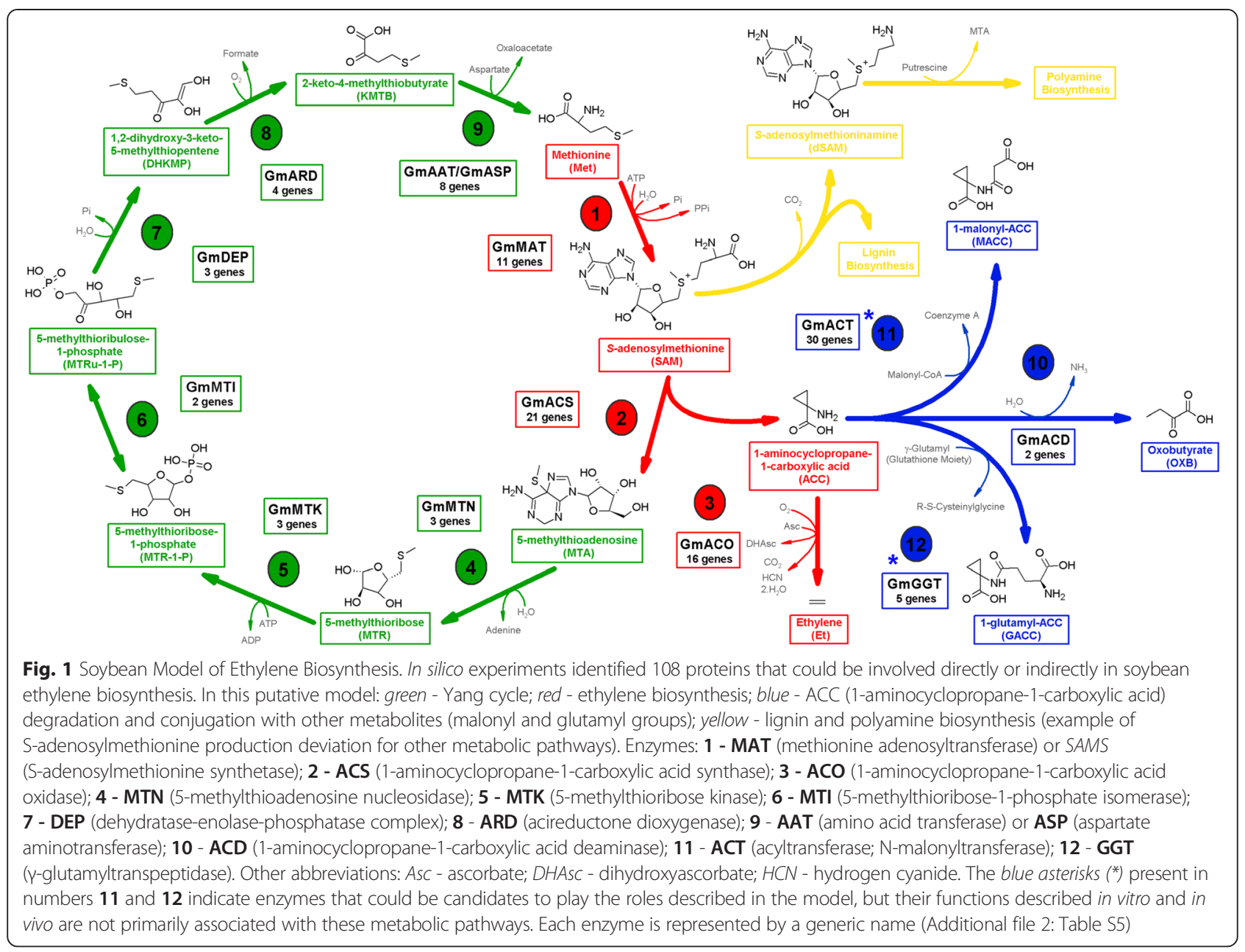

GmACS\#012) (Additional file 2: Table S7; Additional file 1: Figure S4).

Regarding the conversion of ACC into ethylene, sixteen $A C O$ genes were identified in the soybean genome, with 6 of them encoding ortholog proteins in $A$. thaliana and/or O. sativa (GmACO\#004, GmACO\#006, GmACO\#007, GmACO\#008, GmACO\#009 and GmACO\#014) (Additional file 2: Table S7).

Furthermore, ACC can also be used in combination with malonyl and glutamyl in the synthesis of MACC (1-malonyl-ACC) and GACC (1-glutamyl-ACC) [25, 56]. We selected thirty possible candidate genes with this function in soybean, based on six acyltransferases $(A C T)$ from $A$. thaliana and $O$. sativa (Additional file 2: Table S1 and S3). Five were considered BBH-positive with $A$. thaliana and/or O. sativa (GmACT\#003, GmACT\#006, GmACT\#017, GmACT\#020 and GmACT\#023) (Additional file 2: Table S5). It is important to emphasize that although most of the malonyltransferase enzymes play roles in fatty acids, they could also have $\mathrm{N}$-malonyzation activity. Thus, it would be interesting to characterize them in vitro and in vivo after selecting them in silico. With regard to the formation of GACC, five $\gamma$-glutamyl transpeptidases (GGTs) were identified in soybean, and two of them (GmGGT\#001 and GmGGT\#003) were BBH-positive with A. thaliana and O. sativa (Additional file 2: Table S7).

Finally, ACC could be the substrate of ACC deaminase (ACD) in soybean because we identified two genes that codified for homologous ACD enzymes in A. thaliana (GmACD\#001 and GmACD\#002), of which only one was BHH-positive (GmACD\#001) (Additional file 2: Table S7).

Model for soybean ethylene-mediated signal transduction In this work, we identified 68 genes related to ethylenemediated signal transduction. We found that $38.3 \%$ of the proteins coded by these genes had orthologs in A. thaliana and/or O. sativa (Additional file 2: Table S8). The main components of this signal route were represented because $32.4 \%$ were specific receptors (ETR) and proteins important for receptor activity (RTE and RAN), 7.4 \% were CTR, 


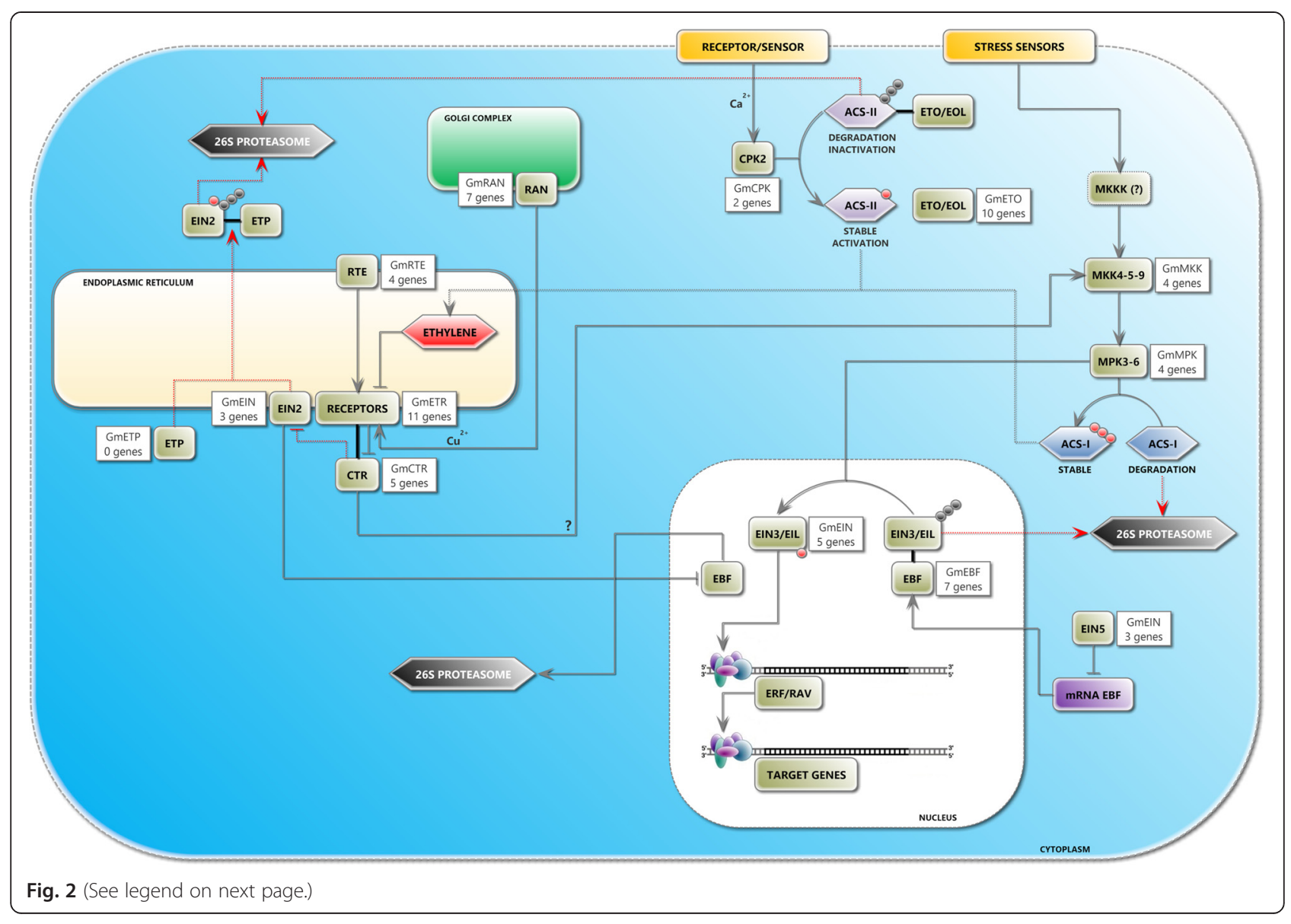


(See figure on previous page.)

Fig. 2 Soybean Model of Ethylene Signal Transduction. In silico experiments identified 68 proteins that could be involved directly or indirectly in soybean signal transduction initiated by ethylene. In this putative model, brown rectangles show the route-identified proteins in $A$. thaliana, and white rectangles show the soybean genes that encode proteins homologous to this plant model; orange rectangles illustrate membrane sensors that respond to biotic and abiotic stress in addition to receptors/sensors for endogenous signals (i.e., other phytohormones); the purple rectangle represents mRNAs related to ETP proteins; the rectangle with dotted outline (accompanied by a question mark) represents a protein in this pathway that has not been identified in the studied plants; blue and purple hexagons represent ACSs types I and II, respectively; black and red circles correspond to ubiquitin and phosphate groups, respectively; gray arrows correspond to routes that occur in the presence of ethylene and/or biotic/abiotic stress; dotted arrows in red and gray represent pathways that occur in the absence of this hormone and routes that culminate in ethylene biosynthesis, respectively; black lines indicate interactions among proteins. Cellular compartments represented: endoplasmic reticulum (beige), Golgi complex (green), nucleus (white) and cytoplasm (blue). Symbols: ACS: 1-aminocyclopropane-1-carboxylic acid synthase; CPK (or CDPK): calcium-dependent protein kinase; CTR: constitutive triple response protein; EBF: EIN3 binding F-Box protein; EIL: EIN protein like; EIN: ethylene insensitive; EOL: ETO protein like; ERF: ethylene response factor; ETP: EIN2 targeting protein; ETO: ethylene overproducer; MKKK (or MAPKKK): MAP kinase kinase kinase; MKK (or MAPKK): MAP kinase kinase; MPK (or MAPK): mitogen-activated protein kinase; RAN: responsive to antagonist; RAV: related to ABI3/VP1; RTE: reversion to ethylene sensitivity. The route of intracellular signal transduction is initiated by the interaction of ethylene with a membrane receptor (encoded by ETR genes) and through the modulation of CTR activity, which regulates the activity of several genes, such as EIN3. The receptors with CTR (similar to the protein kinase RAF - MKKK) work similarly to negative regulators of the pathway and, in the absence of ethylene, suppress downstream positive components of signal transduction. The hormone binding blocks the receptors in an inactive conformation, reducing the repression of metabolic pathway-positive regulators [11]. In the absence of ethylene, CTR phosphorylates the EIN2 C-terminal domain, promoting its interaction with ETP F-box protein (not identified in soybean) and its subsequent degradation via proteasome 26S [30]. In the absence of EIN2 C-terminal phosphorylation (presence of the hormone), this domain is cleaved and moves to the nucleus, where it stimulates EIN3/EIL activity by EBF repression (stimulating the degradation of this F-box protein by unknown mechanisms), which in turn induces target genes transcription through some members of the AP2/ERF superfamily of transcriptional factors [31]. In addition to the interaction with the C-terminus of EIN2, EIN3/EIL activity can be influenced by the MKK4-5-9 $\rightarrow$ MPK3-6 phosphorylation cascade, which is CTR/EIN2-independent. In the presence of a signal, the EIN3/EIL transcriptional factors are phosphorylated by MPK3-6, preventing the interaction with EBF and their degradation via the 265 proteasome. Thus, EIN3 and EIL accumulate in the nucleus, interact with gene target promoters and trigger ethylene responses [33]. Another positive regulator is EIN5, a 5'-3'-exoribonuclease that promotes EBF mRNA decay, increasing the levels of EIN3/EIL in the nucleus [34]. Additionally, ethylene biosynthesis is also regulated. Possible receptors for endogenous signals (i.e., other phytohormones) can induce the secondary metabolites accumulation (i.e., calcium) in an intracellular environment and activate protein kinases (i.e., CPK2), culminating in the stabilization of type II ACSs, an important enzyme in ethylene biosynthesis. Then, type II ACSs (in A. thaliana AtACS5 and AtACS9) are phosphorylated by CPK2, which prevents the interaction of these enzymes with ETO/EOL and their subsequent degradation by the 265 proteasome. This event induces an increase in ethylene production and the activation of signal transduction pathways [109]. Moreover, various stress conditions (biotic and abiotic) induce the activation of MAPK modules (in Arabidopsis thaliana MKK45-9 and MPK3-6). The MPK3 and MPK6 kinases are able to phosphorylate the C-terminal type I ACSs (in A. thaliana AtACS2 and AtACS6), which stabilize and protect these enzymes against 265 proteasome degradation [21]. There is no consensus regarding the direct participation of CTR in a route involving MPK3-6 [39]. The receptor activity is associated with two proteins: RAN, a copper carrier protein (copper is an important cofactor in receptor activity) [110]; and RTE, a protein with an unknown mechanism of action that facilitates the transition among active and inactive states of one receptor, ETR1 [33, 111]. Each protein is represented by a generic name: EIN2: GmEIN\#002, GmEIN\#004 and GmEIN\#007; EIN3: GmEIN\#001, GmEIN\#005, GmEIN\#006, GmEIN\#008 and GmEIN\#010; EIN5: GmEIN\#003, GmEIN\#009 and GmEIN\#011; MKK4: GmMKK\#001 and GmMKK\#003; MKK5: without representatives identified in soybean; MKK9: GmMKK\#002 and GmMKK\#004; MPK3: GmMPK\#003 and GmMPK\#004; MPK6: GmMPK\#001 and GmMPK\#002; Receptors: EIN4: GmETR\#002, GmETR\#004, GmETR\#008 and GmETR\#011; ERS1: GmETR\#001 and GmETR\#007; ERS2: without representatives identified in soybean; ETR1: GmETR\#003 and GmETR\#006; ETR2: GmETR\#005, GmETR\#009 and GmETR\#010 (Additional file 2: Table S6)

$4.4 \%$ were EIN2 proteins, approximately $19.0 \%$ were kinases (CPK, MKK, MPK), $7.4 \%$ were EIN3/EINL transcription factors, $25.0 \%$ were important in proteolysis routes (EBF and ETO), and $4.4 \%$ were orthologs of EIN5 exoribonuclease, which is important for EIN3/EINL activity regulation (Fig. 2; Additional file 2: Table S6).

Four of the five ethylene receptors described in soybean were found to be homologs of ETR1 and ETR2 (subfamily I - GmETR\#001, GmETR\#003, GmETR\#006 and GmETR\#007) and of ERS1 and EIN4 (subfamily II GmETR\#002, GmETR\#004, GmETR\#005, GmETR\#008, GmETR\#009, GmETR\#010 and GmETR\#011) [57-60].

The receptors in soybean have four principal domains similar to those in A. thaliana: (i) receptor response regulation domain (PF00072); (ii) histidine kinase A domain (PF00512); (iii) GAF domain (PF01590); and (iv) histidine kinase $^{-}$, DNA girase $B^{-}$and ATPase-like (PF02518). The different combinations of these four domains comprise the different families of receptors in soybean. For example, the ETR1 homologs have the four domains in their structure because homologs to ETR2 and EIN4 have only the (i), (ii) and (iii) domains and ERS1 has the (ii), (iii) and (iv) domains.

Regarding canonical ethylene signal transduction, we identified five soybean homologs of CTR1, four of RTE genes, seven RAN transporters and three homologs of EIN2 (GmEIN\#002, GmEIN\#004 and GmEIN\#007) (Fig. 2). It is worth mentioning that homologs encoding the ETP proteins could not be found in soybean, suggesting either that other proteins are performing this role or that other mechanisms regulating EIN2 exist but have not yet been discovered. Furthermore, we also found five homologs of EIN3/EIL (GmEIN\#001, GmEIN\#005, GmEIN\#006, GmEIN\#008 and GmEIN\#010) and three 
of EIN5 (GmEIN\#003, GmEIN\#009 and GmEIN\#011) in the G. max genome.

Finally, with regard to the main kinases and F-box proteins related to ethylene signal transduction, thirteen homologs of the kinases were found in the soybean genome, with four of them being homologs of $M K K 4 / M K K 9$, four of $M P K 3 / M P K 6$ and five of $C P K 2$ as well as seven of $E B F$ and ten homologs of ETO/EOL (Fig. 2).

\section{Transcriptional regulation of soybean ethylene genes}

To understand better their transcriptional regulation mechanisms, we performed an in silico analysis of the putative promoter regions of the 176 soybean genes. We identified 14,385 elements in these putative promoters, corresponding to 29 cis-acting element families described in the literature for their transcriptional regulation in different plant species (Fig. 3; Additional file 4: Table S9).

As expected, all of the promoter regions contained elements from $P T P B$ (plants TATA-box) and/or CAAT (CCAAT-box), suggesting that the analyzed sequences have a strong likelihood of being real gene promoters.
Apart from the $P T P B$ and $C A A T$ families, the most represented families in this analysis were those related to transcription factors MYB, MYC and NAC (Additional file 4: Table S9; Fig. 3) and to elements known for heat and light response ( $L R E M$ and $H E A T$, respectively). Interestingly, no cis-acting elements were found from the $R A V 3$ family in any of the putative promoters, indicating that there are possible variations in recognizing the sequence of the B3 domain that is representative of the RAV family in soybean. Another possibility could be that the regulation occurs because of the interaction of the AP2 domain with the RAV5 cis-acting element, which is broadly dispersed in the analyzed regions [61].

The families EINL (ethylene insensitive 3-like) and GCCF (GCC-box) of cis-acting elements are most likely directly related to the regulation of metabolic pathways in which ethylene plays a critical role. EINL and GCCF were present in 63.1 and $11.4 \%$, respectively, of the putative promoters analyzed (Fig. 3). The DREB (dehydration responsive element binding factors) and EREF (ethylene response element factors) elements are known for their

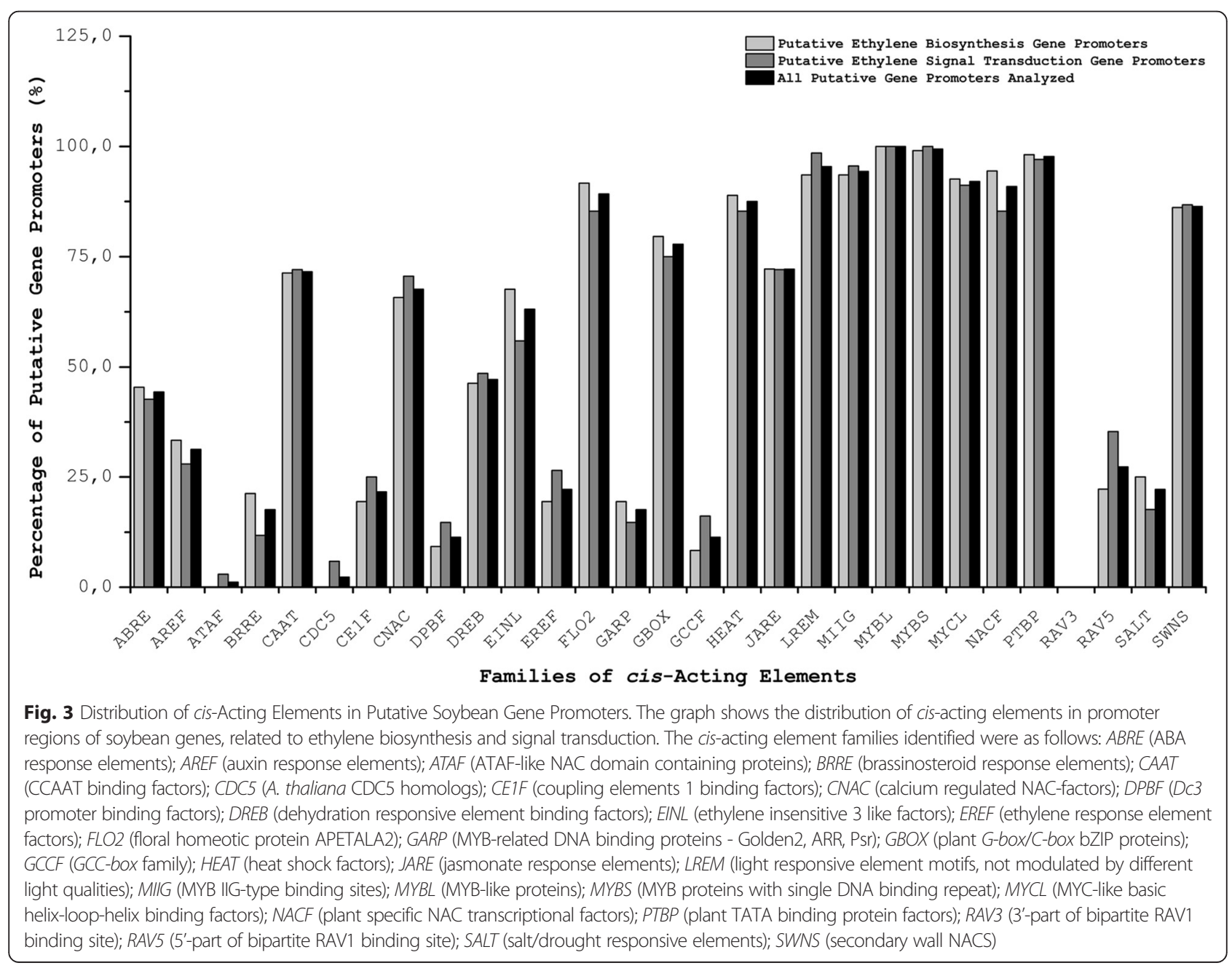


involvement in the response to different stresses, and they were found in 47.2 and $22.2 \%$, respectively, of the analyzed sequences.

When we analyzed the cis-acting elements contained in the putative promoters of the ethylene biosynthesis genes, we observed that $67.6 \%$ had EINL elements and that $8.3 \%$ had GCCF elements. Moreover, other cis-acting elements that respond to other phytohormones were detected, of which the JARE family (jasmonic acid) was present in more than $70.0 \%$ of the putative promoters, followed by the $A B R E$ and CE1F (ABA response) families, which were present in 45.4 and $19.4 \%$, respectively, of the putative promoters. Moreover, $30.0 \%$ of them have elements that respond to auxin (AREF) and $21.3 \%$ to brassinosteroids (BRRE). Finally, the elements DREB and EREF could be detected in 46.3 and $19.4 \%$ of the putative promoters, respectively.

Considering the group with an ethylene-mediated transduction signal, we observed the presence of EINL elements in $55.9 \%$ and GCCF in $16.8 \%$ of the putative promoters. We also detected the JARE element in more than $70.0 \%$ of the sequences analyzed, $A B R E$ and $C E 1 F$ in 42.6 and $25.0 \%$, respectively, the auxin and brassinosteroid response elements in 28.0 and $11.8 \%$, respectively, and the DREB and $E R E F$ elements in 48.5 and $26.5 \%$ of the putative promoters, respectively.

The analysis of the putative promoters showed that the activation or repression of the transcription of a gene in soybean is not likely to be regulated by isolated transcription factors but rather by the interaction of different proteins in a set of DNA-regulatory sequences. In accordance with this hypothesis, this study supported the results of other studies that had proposed crosstalk between the regulation of ethylene metabolism with other development mechanisms, homeostasis and response to various stresses. This affirmation was confirmed by the detection in the possible promoters of different cis-acting elements important for responses to other phytohormones, in addition to elements involved in different biotic and abiotic stress responses (heat shock, pathogen resistance, mechanic injuries, etc.). The presence of cis-acting elements in the 176 global soybean genes analyzed showed that the JARE elements were the most abundant, followed by EINL, DREB and ABRE. The putative promoter analysis indicated that each cis-acting element family could contribute in distinct ways to the regulation of the considered soybean genes: ABRE, EINL, AREF and BRRE are the most represented in the putative promoters of ethylene biosynthesis genes, and JARE, DREB, EREF, CE1F and GCCF are the most represented in the putative promoters of ethylene-mediated signal transduction (Fig. 4). Few $(11.4 \%)$ of the putative promoters presented GCCF cisacting elements (responsive to ethylene), whereas almost half of them had the very similar DREB element, which

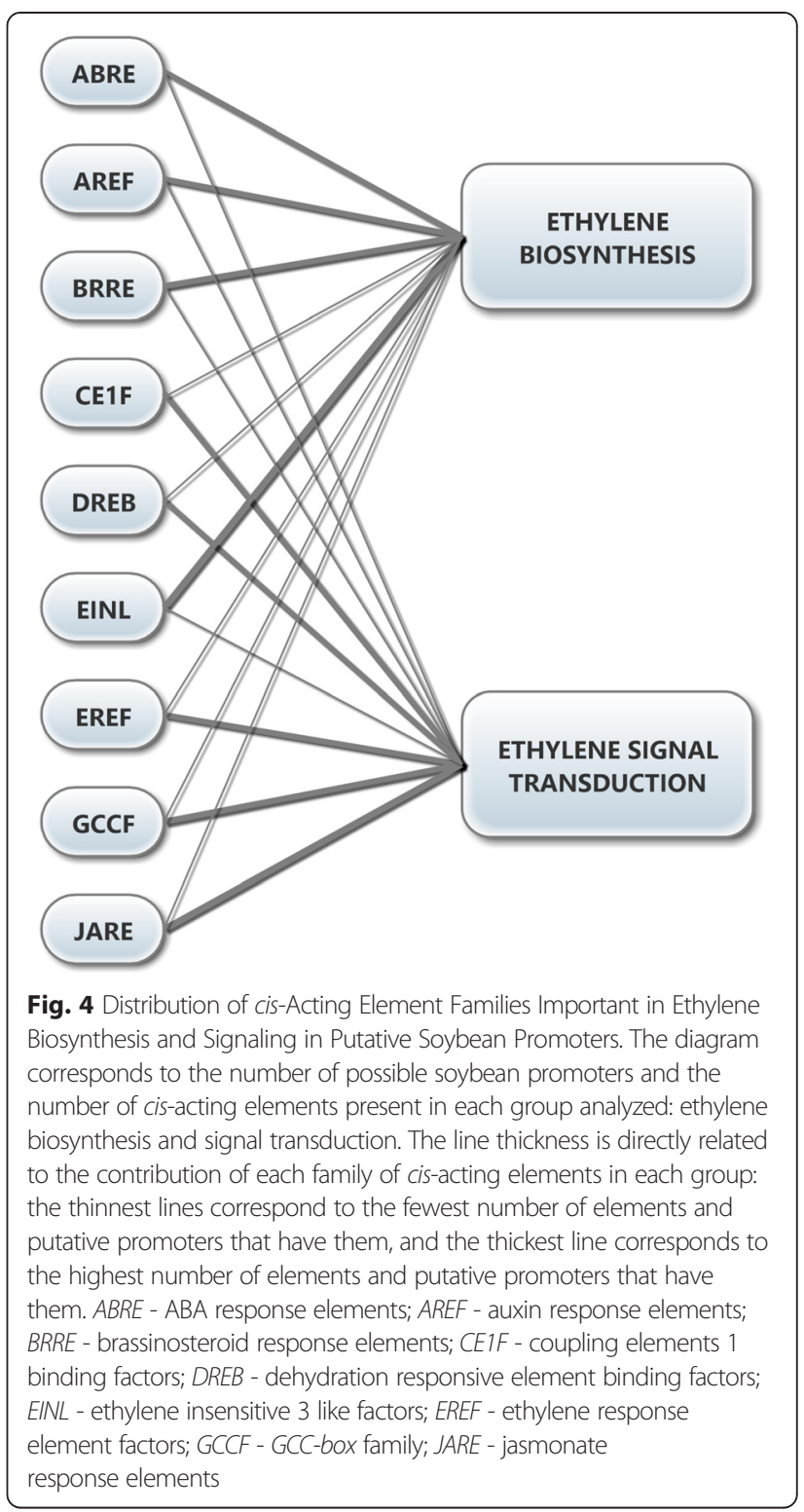

responds first to drought stress. These proportions were the same in the genes that were differentially expressed in drought stress. Recent ChIP (chromatin immunoprecipitation) experiments showed that the transcription factor ERF1 from A. thaliana could interact directly with both cis-acting element families. More interestingly, this transcription factor interacted with GCCF elements under biotic stress conditions and with DREB elements under abiotic stress conditions but never with both at the same time [62].

The data showed that $95.5 \%$ of the putative promoters have the LREM cis-acting element (light-responsive elements, not mediated by different types of light) and that $87.5 \%$ have HEAT elements (heat shock elements) (Fig. 3). In A. thaliana, the response to low light intensity could be regulated by ethylene and auxins (induction of AUX22, 
ACS6, ACS8, ACS9). Similarly, ethylene biosynthesis and ethylene signal transduction, regulated by phytochrome B, are affected by antiphase light and temperature cycles $[63,64]$. Complementary studies with etiolated pea stems showed that in addition to light intensity, red light also regulates ethylene biosynthesis and gravitropism [65]. Additionally, mutants in receptors or orthologs of EIN2 sensitive to ethylene produce high levels of the gas, whereas ctr1-1 mutants produce lower levels of ethylene than wild plants [66]. However, although the double mutants ein3/einl1 have similar phenotypes to ein2 mutants, they produce low levels of ethylene when grown under long day periods but high levels when grown under dark conditions and even lower levels of ethylene than in etr1 and ein 2 mutants [67]. Thus, it is suggested that there is a parallel route to EIN3/EIL that is responsible for the negative control of ethylene biosynthesis, a mechanism that is light dependent. Transcriptional regulation could be associated with the light-responsive transcription factors that interact with LREM elements, which can modulate the response depending on the variation of the G-box sequences that commonly flank the LREM elements [68]. Because more than $77.8 \%$ of the putative promoters have GBOX elements and are associated with a high rate of $L R E M$, we believe that the mechanisms involving EIN3/EINL, its partners or regulated factors, and other light-responsive factors play important roles in the regulation of soybean ethylene biosynthesis.

Many differentially expressed transcripts identified in soybean transcriptomes have been described in the literature as being important in the response to drought. The functions of these transcripts could be associated with not only ethylene biosynthesis and signaling but also with other metabolic pathways. For example, the enzymes responsible for AdoMet production in ethylene biosynthesis also contribute to other metabolic pathways that are ethyleneindependent. Plant polyamines in A. thaliana are involved in the response to different environmental stresses, and recent studies have indicated that polyamine signaling is involved in direct interactions with different metabolic pathways and intricate hormonal crosstalks, such as ABA regulation in response to abiotic stresses [69]. Because MAT (SAMS) enzymes provide the substrate for polyamine synthesis, it is very probable that these enzymes are induced by $\mathrm{ABA}$ in the response to abiotic stresses, as was demonstrated in tomato plants that had high levels of these enzyme transcripts under $\mathrm{NaCl}$ stress conditions and after ABA treatment [70]. Thus, it could be suggested that high levels of $\mathrm{ABA}$ are related to low levels of ethylene because of a possible redirection of AdoMet toward the biosynthesis of polyamines. We observed that among the MAT genes in soybean, $54.6 \%$ have $A B R E$ in their putative promoters, indicating induction of these genes by $\mathrm{ABA}$ in response to abiotic stresses.
The presence of elements responsive to other phytohormones must also be considered in the regulation of ethylene biosynthesis. Zhang and coworkers [71] demonstrated that ABA could induce the genes that encode the enzymes ACC synthase and ACC oxidase, stimulating ethylene biosynthesis and fruit ripening [71]. Additionally, studies have shown that one of the first actions of auxins is the induction of $A C S s$, which increase ethylene production [72]. Along with auxins, brassinosteroids and methyl-jasmonate could also induce ACO enzymes, increasing ethylene production in maize and olive plants $[73,74]$.

These studies with putative soybean promoters are important not only for a better understanding of ethylene signaling in this crop but also for the production of genetically modified plants with genes regulated under different stress conditions separately and/or simultaneously.

\section{Analysis and validation of soybean transcriptomes in water deficit conditions \\ Transcriptome databank analysis of water deficit contrasted with soybean genotypes}

To investigate the expression of soybean genes, we studied the transcriptome of two cultivars with contrasting responses to drought stress (sensitive to drought BR16 and tolerant to drought EMBRAPA48). The plants were grown hydroponically and under different water stress conditions. The transcriptomes, provided by the GENOSOJA project, were constructed using subtraction library hybridization (SSH), which detects differential expression of transcripts under water stress. In this database, $40.9 \%$ of the genes identified were expressed differentially in at least one of the listed situations. Among them, $43.1 \%$ were related to ethylene biosynthesis and $56.9 \%$ to its signal transduction (Additional file 1: Figure S5 and S6). Furthermore, we found that $25.0 \%$ of differentially expressed genes were detected in sensitive BR16, $47.2 \%$ were detected in drought-resistant EMBRAPA48, and $27.8 \%$ were present in both cultivar databases. These contrasting results might be explained by the genetic basis of each cultivar providing the relative variations in the gene expression or by a discrepancy between the obtained unique sequences and the cultivar databases (42.3 million unique sequences generated, of which $27.8 \%$ are from BR16 and $72.2 \%$ from EMBRAPA48) [75].

We observed that $37.5 \%$ of the differentially expressed genes were detected uniquely in roots (among which $3.7 \%$ were from BR16 and $96.3 \%$ were from EMBRAPA48), $26.4 \%$ were detected exclusively in leaves (among which $84.2 \%$ were from BR16, 10.5 \% were from EMBRAPA48, and $5.3 \%$ were found in both cultivar databases), and $36.1 \%$ were expressed in both roots and leaves. These results, together with the normalized data presented (Additional file 1: Figure S7), suggested that the 


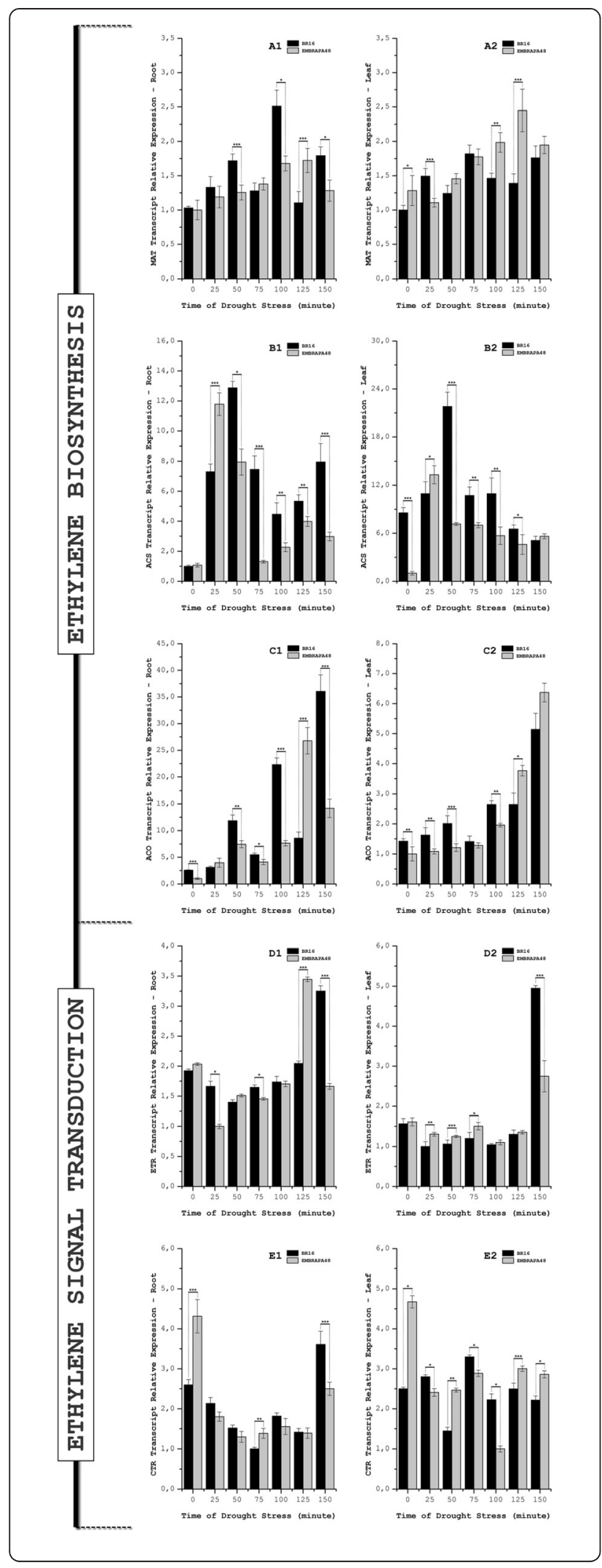

Fig. 5 Expression of Ethylene-Related Genes in Soybean Under Drought Stress Conditions. The graphs show the expression levels, obtained by RT-GPCR, of five soybean genes related to ethylene biosynthesis [MAT (a), ACS (b) and ACO (c)] and ethylene signal transduction [ETR (d) and CTR (e)]. The expression of these genes in the experiment was compared in roots and leaves of soybean cultivars BR16 and EMBRAPA48 after different durations of drought stress. In the column graphs 1 and 2, the statistical analysis was performed by comparing similar tissues in both cultivars under the same conditions of drought stress (same durations). The asterisks represent the level of statistical significance: $\left(^{*}\right) p \leq 0.05$; (*) $0.01 \leq p<0.05 ;(* *) 0.001 \leq p<0.01$. Each dot represents the average amount ( \pm standard error) of three experimental replicates (same sample) in three biological samples (different plants), totaling nine replicates. The standard error is not presented with some of the dots because their absolute values are lower than the scale. After normalization based on housekeeping genes, the values given in the graph are relative to the lowest expression, whose value was set at 1 (one). Information about the target genes is presented (Additional file 6: Method S1)

expression of genes in the roots was preferentially observed in the drought-tolerant EMBRAPA48, whereas in the leaves, the differential expression was more proportionate depending on the group of genes and the duration of stress.

Furthermore, the expression of both groups of genes was analyzed. We observed that $28.7 \%$ of the biosynthesis genes were expressed in roots and leaves of the sensitive and tolerant cultivars. Among them, $16.1 \%$ were expressed in only sensitive BR16, mainly in the leaves. Conversely, $43.9 \%$ differential expression was detected exclusively in tolerant EMBRAPA48, mainly in the roots (Additional file 1: Figure S5).

In ethylene-mediated signal transduction, $61.8 \%$ of the genes were differentially expressed under water stress conditions. In the sensitive cultivar, $33.3 \%$ were differentially expressed, mostly in the leaves, and in the tolerant cultivar, $42.9 \%$ had a differential expression, mainly in the roots (Additional file 1: Figure S6).

\section{Transcriptome functional validation of the candidate genes}

To validate the data obtained in silico, the levels of some differentially expressed genes were assessed by RT-qPCR in both leaf and root tissues exposed to drought stress. The plants were grown under the same conditions as those used for transcriptome analysis. The $C_{t}$ (cycle threshold) values obtained are listed (Additional file 5 : Table S10 and S11).

The expression of the genes MAT, ACS and ACO were found to have the same differential trends as the data obtained in silico, although with variations in the expression profiles (Fig. 5a, b and c. Additional file 1: Figure S8a, S8b and S8c). This result could be due to limitations in the construction of the GENOSOJA subtractive libraries and general experimental variations. As an example, the expression of $A C S$ is different in both cultivars and tissues with RT- 
qPCR, but it was detected in only the transcriptome of the roots of EMBRAPA48.

Induction kinetics analysis of soybean ACS and $A C O$ genes confirmed the temporality of the metabolic reactions catalyzed by these enzymes in both cultivars because ACS gene expression reached its peak earlier than that of the $A C O$ gene (Fig. $3 b$ and c). Furthermore, when comparing the two soybean varieties, the expression of these two genes was observed earlier in the drought-tolerant cultivar. This fact could be evidence of ethylene participation in soybean responses to water stress.

The same analysis was performed with the genes coding ethylene receptors $(E T R)$ and for the protein kinase CTR (Fig. 5d and e. Additional file 1: Figure S8d and S8e). Few differences were observed in the expression patterns of the transcripts of these genes between the cultivars. In the roots of both cultivars, there was a reduction in the level of ETR transcripts, comparing stressed and non-stressed plants. The maximal expression was achieved under the longest periods of stress. In the same tissue, the transcripts of CTR were reduced, with a significant increase detected only after $150 \mathrm{~min}$ of water deficit in both cultivars. In the leaves, when comparing the stress and no-stress conditions, we were able to observe a slight reduction in the levels of transcripts of ETR in the first $125 \mathrm{~min}$ of drought and a peak elevation at the end of the analysis $(150 \mathrm{~min})$. Relative to the CTR transcripts, it was observed that the expression of the drought-tolerant cultivar was higher in the non-stressed state (time zero).

\section{Levels of free ACC and ethylene production}

To compare and correlate the data obtained in silico with the physiological data, we assessed the levels of free ACC and ethylene in both BR16 and EMBRAPA48 cultivars. The plants were grown under similar conditions as those used for the analysis of transcriptomes. The physiological data showed that both of the cultivars suffered under the water deficit but that the tolerant cultivar responded better, exhibiting increases in the photosynthetic rate, stomatal conductance and evapotranspiration after $75 \mathrm{~min}$ of stress (Additional file 1: Figure S9). The water consumption (WUE) showed that before $75 \mathrm{~min}$ had elapsed, the sensitive cultivar was using its water resources better than the tolerant cultivar, but subsequently, the situation was reversed; thus, the stress caused a greater impact on the susceptible cultivar.

We analyzed the levels of free ACC and ethylene production and found, in general terms, that free ACC was mostly increased in the leaves, whereas ethylene was mostly increased in the roots (Fig. 6 and Additional file 1: Figure S10). We observed that the EMBRAPA48 cultivar had higher levels of free ACC in the leaves and variable levels in the roots. In the roots of non-stressed plants (time zero), the free ACC was higher in BR16 plants, and the ethylene production was higher in the EMBRAPA48 cultivar (Fig. 6a and b. Additional file 1: Figure. S10a and $\mathrm{S10b})$, whereas in the leaves, the level of free ACC was the same in both cultivars, and the quantity of ethylene production was higher in EMBRAPA48 (Fig. 6 a2 and b2). Except for the period of $25-50 \mathrm{~min}$ of stress, it was observed that both free ACC and ethylene production exhibited cyclic behavior in both the leaves and roots of BR16: when free ACC increased, ethylene decreased, and vice versa. Additionally, in BR16, we found that in both tissues, the peak of ethylene production $(75 \mathrm{~min}$ ) corresponded to the lowest value of free ACC. In the EMBRAPA48 cultivar, this cyclic pattern was much less evident. We observed that the highest peaks of free ACC were found after $75 \mathrm{~min}$ in the roots and after $125 \mathrm{~min}$ in the leaves, whereas the maximal production of ethylene corresponded to 75 and $150 \mathrm{~min}$ of stress, respectively. In the leaves, the maximal peak of ethylene production occurred at time zero.

When we compared the levels of ethylene production and free ACC, two different situations were observed. First, an increase in free ACC coincided with an increase in ethylene production. Although the hydrolysis of ACC aggregates remains contradictory, the high level of free ACC could be explained by the degradation of these aggregates of malonyl-ACC into free ACC, accompanied by an increase in free ACC production and the conversion of AdoMet into ACC by the ACS enzyme. Thus, the levels of free ACC would exceed the capacity of ACO enzymes to convert it into ethylene, which would be present at its maximal level $[23,76,77]$. Conversely, we observed a reduction of the levels of free ACC, together with a reduction in ethylene production. This finding could be explained by the formation of malonylACC and glutamyl-ACC, accompanied by the degradation of the ethylene precursor by ACD enzymes. To support this conclusion, we simultaneously detected the differential expression of GmGGT\#002 in the roots and leaves of both cultivars and GmACD\#001 in the roots of EMBRAPA48. To understand this trend better, it would be necessary to characterize the molecular pathways involved in ACC conjugation and degradation in vitro and in vivo to determine the precise mechanisms underlying the regulation of ethylene biosynthesis in response to diverse signals, in addition to the identification of the actual role of the formation of ACC aggregates in this case.

In our work, transcriptome analysis, RT-qPCR and ethylene production revealed that ethylene synthesis depended on the tissue analyzed. After $75 \mathrm{~min}$ of water deficit, the maximal production of ethylene was observed in 


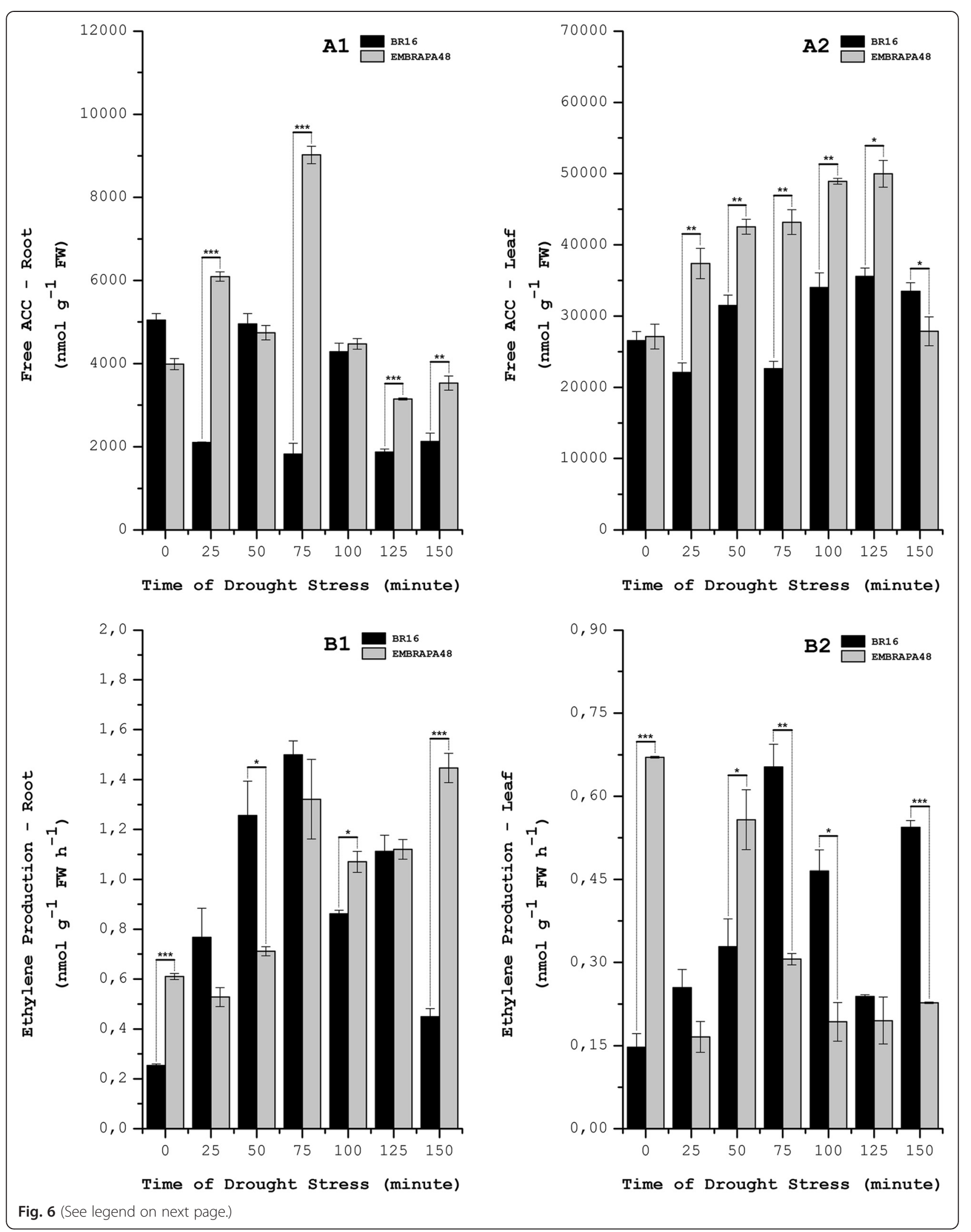


(See figure on previous page.)

Fig. 6 Levels of Ethylene Production and Free ACC in Soybean Under Drought Stress Conditions. Values were determined for ethylene production and free ACC (1-aminocyclopropane-1-carboxylic acid) in roots and leaves of soybean cultivars BR16 and EMBRAPA48 after the application of different durations of drought stress. The codes $\boldsymbol{a} \mathbf{1}$ and $\boldsymbol{a} \mathbf{2}$ represent levels of free ACC; $\boldsymbol{b} \mathbf{1}$ and $\boldsymbol{b} \mathbf{2}$ represent levels of ethylene production. The statistical analysis was performed by comparing similar tissues in both cultivars under the same conditions of drought stress (same durations). The asterisks represent the level of statistical significance: $\left(^{*}\right) p \leq 0.05 ;(* *) 0.05<p \leq 0.01 ;(* *) 0.01<p \leq 0.001$. Each dot represents the average amount ( \pm standard error) of three replicates in different plants. The standard error is not presented with some dots because their absolute values are lower than the scale

leaves of BR16, whereas after the same period of water deficit, in the leaves of EMBRAPA48, ethylene exhibited a significant decrease. In the roots, both cultivars had high levels of ethylene production (Fig. 6). Together with only the tolerant cultivar displaying an increase in stomatal conductance, photosynthetic rate and transpiration after the same stress period (Additional file 1: Fig. S9), these findings indicated that in this situation, leaves and roots undertake different responses to ethylene. Additionally, we can suggest that in the leaves, ethylene production could be associated with the response to drought stress because ethylene could regulate stomatal closure [78].

Nonetheless, studies have shown that the levels of this phytohormone are low when plants are exposed to water deficit $[79,80]$. These conflicting observations could be attributed to the system in which the soybean plants were grown. The plants were grown hydroponically, with the roots submerged in a nutrient-containing solution. Some studies have shown that variations in gene expression could occur when hydroponic and soil cultures were compared [42]. Thus, it is believed that hydroponically grown roots have molecular responses similar to those of roots grown under flooding conditions and that when subjected to water deficit, they exhibit molecular responses different from those shown by roots grown via soil culture.

Additionally, other works have reported that in plants grown under flooding conditions, the levels of ethylene production were higher than those obtained under water deficit conditions [81]. We also believe that a natural elevation of the temperature caused by rapid water loss could be explained by an increase in ethylene biosynthesis because the activity of enzymes was also rapidly increased, as shown by Antunes and Sfakiotakis [82]. Because ethylene diffusion is more rapid in the air than in liquid (Hoagland's solution) and because water deficit and dehydration are more rapid under hydroponic conditions, we believe that the plants do not have sufficient time to begin molecular responses before desiccation occurs. One explanation could be that when short intervals of water deficit (25-50 $\mathrm{min}$ ) are applied, ethylene biosynthesis and signal transduction remain similar to those under normal growing conditions. Therefore, when the stress duration is increased, the signal transduction could be strongly decreased. In fact, the plants were switched from flooding stress to water deficit stress, possibly activating different responses that substituted for the normal water deficit responses because we observed the differential expression of many genes even before the stress was administered. Thus, the analysis of the GENOSOJA database would be best complemented by nextgeneration sequencing experiments to replace the $\mathrm{SSH}$ methodology and cultivation in pot systems, instead of under hydroponic conditions.

\section{Conclusions}

This study was the first to propose accurate models for ethylene biosynthesis and signaling in the soybean. Based on the currently available databases, soybean genes and proteins homologous to almost all of the components of the pathways featured in $A$. thaliana were identified, with the exception of the ETP gene. The cis-acting elements present in soybean putative promoters were described to infer possible models and the regulation of signaling pathways linked directly to ethylene as well as their communication with other metabolic routes. RT-qPCR experiments were important to the validation of soybean transcriptome data and allowed for the evaluation of the induction kinetics of $A C S$ and $A C O$ soybean genes. Finally, changes were observed in the levels of production of ethylene and its precursor (in its free form) in soybean cultivars under water stress conditions.

By the integration of all data, many inferences could be made, among which the involvement of ethylene in soybean water stress responses stands out. Furthermore, this work showed that regulation of the ethylene-mediated response could be influenced by diverse exogenous and endogenous factors, indicating that the balance of these various factors determines the quality and intensity of different stimuli responses. Further studies are necessary to continue elucidating in vivo molecular mechanisms involved in ethylene coordination in soybean both to confirm our observations and to facilitate biotechnological strategies for the improvement of cultivar tolerance to various stresses.

\section{Methods}

\section{Functional annotation}

Based on the Genbank TAIR (The Arabidopsis Information Resource; http://www.arabidopsis.org/) [83], we selected the genes related to ethylene biosynthesis and signaling in 
Arabidopsis thaliana. A BLAST (Basic Alignment Search Tool) search was performed with the amino acid (amino acid sequences, equal or over 200 bits score, against protein sequence databases: Glycine $\max$ [L.] Merrill (GENOSOJA: http://www.lge.ibi.unicamp.br/soybean/; SoyBase: http:// soybase.org/; Phytozome version 9.1: http://www.phytozo me.net/) and Oryza sativa Nipponbare (Rice Genome An notation Project; http://rice.plantbiology.msu.edu) [84-86].

Subsequently, 176 soybean genes were ranked in three groups according to their ontology with Blast $2 G O$ software (Gene Ontology) [87]: (i) cell component, with suggestions about their active locations at the cellular and macromolecular complex substructure levels; (ii) molecular function, with descriptions of their the catalytic activity or binding at the molecular level; and (iii) biological processes, with descriptions of their biological objectives according to one or more ordered sets of molecular features. For this purpose, the soybean nucleotide sequences of each gene were processed with the aid of the Blast $X$ tool (used to search the database according to the nucleotide sequences translated into all six possible reading phases) using the $A$. thaliana protein sequences as a database and only selecting those with an $e$-value $\leq e^{-10}$. After the annotation, the functionality of the sequences was analyzed with the aid of the online tool InterproScan version 5.0 [88] and finally determined by the online software GO Ontology-Slim [89].

The protein domain analysis of the amino acid sequences of the genes selected in the three studied organisms was performed using the PFAM (Protein Family; http://pfam.x fam.org/) bioinformatic tool [90]. The selection parameter $(e$-value $<1.0)$ used was the same one defined by this program's website.

The ideogram representing the location of the 176 soybean genes analyzed in the 20 chromosomes was built in proportion to the chromosome size $(1.0 \mathrm{~cm}$ corresponds to 5.0 megabase), taking into account the location of each gene and the DNA strand in which they are localized (sense and antisense). The positions of the centromeres and the size of each chromosome were obtained from a reference genome [91].

The sequence alignment analysis and dendrogram construction were performed with the programs BIOEDIT version 7.0.9.0 and MEGA version 5, respectively. The Neighbor-joining analyses were used to calculate the distance matrices for dendrogram construction. Bootstrap analysis with $10^{4}$ replicates was performed to test the robustness of the internal branches. The proposed models for ethylene biosynthesis and signaling in soybean were obtained from the SoyCyC version 3.0 (Soybean Metabolic Pathway Database; Soybase; http://www.soybase.org:8082/) and KEGG (Kyoto Encyclopedia of Genes and Genomes; http://www.genome.jp/kegg/) [92, 93].

The possible protein phosphorylation sites by MAP kinases (MAPK) and calcium-dependent protein kinase present in the 1-aminocyclopropane-1-carboxylic acid synthase (ACSs) type I and type II, respectively, were determined by the online program NetPhos version 2.0 (http:// www.cbs.dtu.dk/services/NetPhos/) [94]. The presence of possible phosphorylation sites was analyzed in the Cterminal region using the amino acids tyrosine, serine and threonine.

Each protein sequence identified in the soybean databases ( $A$ sequence) was compared individually with those from A. thaliana (TAIR) and rice (Rice Genome Annotation Project) to obtain the homologous $B$ and $C$ sequences, respectively. The BBH (Best Bidirectional Hit) criterion was used, and positive hits were obtained when $B$ and/or $C$ sequences were compared with the soybean database; the best similarity was with the $A$ sequence. Gene duplication was considered to avoid false negatives [95].

The presence of cis-acting elements in putative promoter regions was examined [2000 pairs upstream of the open reading frame bases (ORF)] for each soybean gene selected for this study. This analysis was performed using the bioinformatics tool MatInspector version 8.0 (Genomatix ${ }^{\circ}$ ) using "plants" as matrix group, " 0.85 " as the value for the similarity of the main bases that constitute each cis-acting element (core similarity), and "Optimized +1 " as the value for the similarity matrix (similarity matrix) [96].

The expression of each gene involved in the biosynthesis and signaling of the ethylene metabolic pathway was accessed in the GENOSOJA database [75]. The gene expression levels were represented in graphics indicating the FPKM (fragments per kilobase of exon per million fragments mapped) normalized read counts for each gene that was differentially expressed in the twelve cDNA libraries (25-50, 75-100 and 125-150 min of drought stress).

\section{Plant growth and physiological parameters}

Soybean seeds from BR16 and EMBRAPA48, which are sensitive and tolerant to water deficit [97, 98], respectively, were germinated on filter paper (Germitest) for seven days in a growth chamber at $25.0 \pm 1.0{ }^{\circ} \mathrm{C}$ and $100.0 \%$ relative humidity (RH). The seedlings were transferred to $36 \mathrm{~L}$ boxes containing $50.0 \%$ Hoagland's solution [99], which was continuously aerated and replaced weekly. The plantlets were grown until V5 stage [100] in a greenhouse under a natural $12 \mathrm{~h}$ photoperiod at $30.0 \pm 5.0^{\circ} \mathrm{C}$ and $60.0 \pm 10.0 \% \mathrm{RH}$. The experimental design was a randomized complete block in a $2 \times 7$ factorial arrangement involving two cultivars (BR16 and EMBRAPA48) and seven water deficit periods $(0,25,50,75,100,125$ and $150 \mathrm{~min})$, respectively, with three replicates. The stress was imposed by removing the plants from the hydroponic solution and leaving them without nutrient solution for up to 150 min under air exposure conditions. For each water deficit period, root and leaf 
samples were collected from three plants, pooled and frozen in liquid nitrogen before storage at $-80^{\circ} \mathrm{C}$.

The photosynthetic rate $(A)$, photosynthetically active radiation $(P A R)$, internal $\mathrm{CO}_{2}$ concentration $\left(C_{i}\right)$, stomatal conductance $\left(g_{s}\right)$ and transpiration rate $(E)$ were evaluated using a LI-6400 Portable Photosynthesis System (Li-Cor, Inc.). The parameters were measured in triplicate on the youngest trifoliate leaf that was totally expanded under a photon flux density of $1300 \mu \mathrm{mol} \mathrm{m}{ }^{-2} \mathrm{~s}^{-1}$. The temperature variation $(\Delta T)$ was measured by the difference between the air $\left(T_{a r}\right)$ and leaf $\left(T_{\text {leaf }}\right)$ temperatures. The water use efficiency (WUE) was determined by the ratio between $A$ and $E$. The data were statistically analyzed by ANOVA using the SAS and SANEST (Statistical Analysis System version 8.0) softwares, and the treatments were compared by Tukey's test $(p \leq 0.05)$.

\section{Total RNA extraction and quantitative real time PCR (RT-qPCR)}

Total root and leaf RNA from BR-16 and EMBRAPA48 of each treatment was extracted in triplicate using the Trizol (Invitrogen) protocol and treated with DNAse I (Invitrogen, Inc.). Total mRNAs were utilized as templates for cDNA synthesis using the enzyme Moloney Murine Leukemia Virus Reverse Transcriptase (M-MLV RT) (Invitrogen, Inc.).

Quantitative real-time PCR was performed to validate the genes related to ethylene biosynthesis (MAT, ACS and $A C O)$ and signaling (ETR and CTR) pathways in soybean. Primers were designed by Primer 3 Plus [101] software and checked for the presence of putative amplicons from 120 to $200 \mathrm{pb}$ and melting temperature $\left(\mathrm{T}_{\mathrm{M}}\right)$ of $60.0 \pm 2.0{ }^{\circ} \mathrm{C}$ (see Additional file 6: Method S1). To establish the normalization factor, two reference genes were used for root samples $(A C T 11$ and $U B C 2)$ and two for leaf samples (CYP2 and ELF1A) [102, 103]. All experiments were carried out in experimental and biological triplicate. The quantitative real-time PCR amplifications were performed using the ABI Real Time PCR System 7500 Fast (Applied Biosystem, Inc.) thermal cycler with a comparative cycle threshold $\left(\Delta \Delta \mathrm{C}_{\mathrm{t}}\right.$ ). Rox Plus SYBR Green Master Mix $2 X$ (LGC Inc.) was combined with 4.0 or $10.0 \mu \mathrm{M}$ of each primer (sense and antisense) and $2.0 \mu \mathrm{L}$ of cDNA (40 or 80 -fold dilution) for each experimental condition (Method S1). The PCR cycling conditions were $95{ }^{\circ} \mathrm{C}$ for $15 \mathrm{~min}$ to activate the hot-start Taq DNA polymerase, 40 cycles at $95^{\circ} \mathrm{C}$ for $30 \mathrm{~s}$, $60{ }^{\circ} \mathrm{C}$ for $30 \mathrm{~s}$ and $72{ }^{\circ} \mathrm{C}$ for $3 \mathrm{~min}$ (final extension). The raw fluorescence data for all runs were imported into the Real-Time PCR Miner software [104] to determine the $C_{t}$ value and the PCR efficiency. The $C_{t}$ values were converted by qBASE v.1.3.5 software [105]. The statistical analysis was performed using the REST 2009 (Relative Expression Software Tool - Qiagen, Inc.) software [106] in two ways: first by comparing the relative gene expression values between both cultivars in the same tissue under the same stress conditions and second by comparing the control (without stress) with the stressed samples of the same cultivar.

\section{Determination of ethylene production}

For ethylene analysis, $0.5 \mathrm{~g}$ root and leaf samples were collected for each stress period in $50 \mathrm{~mL}$ glass recipients and sealed with a silicone lid. After $24 \mathrm{~h}$, the ethylene analysis was performed. First, a $1.0 \mathrm{~mL}$ sample of each treatment was obtained using a gastight syringe, and its concentration was determined by a gas chromatograph (GC) equipped with a flame ionization detector (FID), as described by Mainardi et al. [107]. The GC column used was HP-Plot Q (30 m, D.I. $0.53 \mathrm{~mm})$, and the injection conditions were a pressure of 20.0 psi for $2 \mathrm{~min}$, ventilation flux of $20.0 \mathrm{~mL} \cdot \mathrm{min}^{-1}$ after $30 \mathrm{~s}$ and injector temperature of $200{ }^{\circ} \mathrm{C}$. An isothermal program was run at $30{ }^{\circ} \mathrm{C}$, employing constant fluxes of helium gas of $1.0 \mathrm{~mL} \mathrm{~min}{ }^{-1}$, a detector temperature of $250{ }^{\circ} \mathrm{C}$ and detector air and hydrogen fluxes of $400.0 \mathrm{~mL} \mathrm{~min}^{-1}$ and $40.0 \mathrm{~mL} \mathrm{~min}^{-1}$, respectively. The ethylene production was estimated in relation to the injection of $0.1 \mu \mathrm{L} \mathrm{L}^{-1}$ of ethylene in synthetic air (Air Liquid Ltd.), and it was represented in nmoles for grams of fresh weight for hour $\left(\mathrm{nmol} \mathrm{g}^{-1} \mathrm{FW} \mathrm{h}^{-1}\right)$.

\section{Determination of free 1-Aminocyclopropane-1-Carboxylic Acid (ACC)}

Liu and coworkers [108] proposed the method for the determination of free ACC [108]. The samples were composed of roots and leaves from both cultivars, collected in triplicate, from different plants, stored in $50.0 \mathrm{~mL}$ Falcon tubes and frozen in liquid nitrogen $\left(\mathrm{N}_{2}\right)$. Approximately $0.5 \mathrm{~g}$ of each sample was crushed with $\mathrm{N}_{2}$, and the powder was transferred to $5.0 \mathrm{~mL}$ of a $60.0 \%$ methanol solution $(\mathrm{v} / \mathrm{v})$. The samples were stirred for one hour under ambient temperature and centrifuged at $14000 \mathrm{x}$ g for $10 \mathrm{~min}$ at $25{ }^{\circ} \mathrm{C}$. The supernatant was transferred to another tube. The residue was resuspended in $200.0 \mu \mathrm{L}$ of ultrapure water and transferred to a $1.5-\mathrm{mL}$ microcentrifuge tube, to which was added $300.0 \mu \mathrm{L}$ of $200.0 \mathrm{mM}$ borate buffer at $\mathrm{pH} 8.0$ and $360.0 \mu \mathrm{L}$ of $1.0 \mathrm{mM}$ fluorescamine dissolved in acetone. The mixture was vigorously stirred, maintained at $25{ }^{\circ} \mathrm{C}$ for $10 \mathrm{~min}$ and then filtered through a 0.45 micron porous membrane into a $2.0 \mathrm{~mL}$ glass vial. A $20.0 \mu \mathrm{L}$ aliquot of the filtered mixture was injected into a liquid chromatograph coupled with a fluorescence detector (Agilent 1100). The sample was eluted through a C18 Luna column (5.0 microns, $300 \times 4 \mathrm{~mm}$, Supelco, SigmaAldrich, USA), and the effluent was monitored at an excitation wavelength of $378 \mathrm{~nm}$ and an emission wavelength of $475 \mathrm{~nm}$. The results were calculated 
according to an external standard curve of standard ACC (Sigma-Aldrich, USA) in the range from 0.1 to $10.0 \mu \mathrm{g}$. The determination of free ACC is given in nmoles for gram of fresh weight $\left(\mathrm{nmol} \mathrm{g}{ }^{-1} \mathrm{FW}\right)$.

\section{Additional files}

Additional file 1:Supplementary Figures (Figs. S1-S10). Figure S1. Soybean Chromosomal Ideogram; Figure S2. Gene Ontology

Classification; Figure S3. Protein Orthology by Best Bidirectional Hit (BBH) Analysis; Figure S4. ACSs Classification; Figure S5. Differential Expression of Genes Related to Soybean Ethylene Biosynthesis in

Transcriptomes Under Drought Stress Conditions; Figure S6. Differential Expression of Genes Related to Soybean Ethylene Signal Transduction in Transcriptomes Under Drought Stress Conditions; Figure S7. Comparison of Ethylene Biosynthesis and Signaling Differential Gene Expression Among Similar Tissues in Soybean Cultivars Under Drought Stress Conditions; Figure S8. Expression of Ethylene-Related Genes in Soybean Under Drought Stress Conditions; Figure S9. Evaluation of Physiological Parameters in Soybean Cultivars Under Drought Stress Conditions; Figure S10. Levels of Ethylene Production and Free ACC in Soybean Under Drought Stress Conditions. (PDF $3938 \mathrm{~kb}$ )

Additional file 2: Protein Summarys and Best Bidirectional Hit (BBH) Results (Tables S1-S8). Table S1. Protein Summary and Best Bidirectional Hit (BBH) Results. Arabidopsis thaliana ethylene biosynthesis protein list; Table S2. Arabidopsis thaliana ethylene signal transduction protein list; Table S3. Oryza sativa ethylene biosynthesis protein list; Table S4. Oryza sativa ethylene signal transduction protein list; Table S5. Soybean ethylene biosynthesis protein summary; Table S6. Soybean ethylene signal transduction protein summary; Table S7. BBH Experiment - Soybean ethylene biosynthesis proteins; Table S8. BBH Experiment Soybean proteins related with ethylene signal transduction. (PDF $1233 \mathrm{~kb})$

Additional file 3: In silico Characterization of Ethylene Soybean Genes. Detailed description of characterization, gene localization and gene onthology (GO) of ethylene soybean genes. (PDF $12 \mathrm{~kb}$ )

Additional file 4: Identification of $c$ is -Acting Elements in Soybean Putative Gene Promoters (Table S9). In this table are shown the cisacting elements present in the putative promoters of 176 analyzed genes. The analysis matrix was composed by 100 different elements, distributed in 29 families. Cells highlighted in different colors corresponding to elements in each promoter sequence identified associated with the number of the identified elements. Thus, sequences with green and red cells respectively represent putative gene promoters in ethylene biosynthesis and signal transduction mediated by this plant hormone. All results are presented in three ways: the total number of matches for each cis-acting element in the matrix analyzed (column E); the number of different sequences of putative promoters that represent each cis-acting element that compose the matrix (column F); and, at last, the number of different sequences of putative promoters that represent each cis-acting element family (column G). These values are totaled, and the total number of matches identified in each sequence analyzed (line 107). (**) N.A. corresponds to not applicable. (XLSX 84 kb)

Additional file 5: Real Time PCR (RT-qPCR) Cycle Threshold ( $\left.C_{t}\right)$ (Tables S10-S11). Table S10. Target and endogenous gene cycle threshold in soybean leaf under drought stress - RT-QPCR; Table S11. Target and endogenous gene cycle threshold in soybean root under drought stress - RT-qPCR. (PDF $326 \mathrm{~kb}$ )

Additional file 6: Real Time PCR (RT-qPCR) Primers (Method S1). Gene summary and primers for Real Time PCR. (PDF 227 kb)

\section{Abbreviations}

AAT: Amino acid transferase; ABA: Abscisic acid; ABR: ABA repressor; ABRE: ABA response elements; ACC: 1-aminocyclopropane-1-carboxylic acid: ACD: ACC deaminase; ACO (EFE): ACC oxidase (ethylene forming enzyme); ACS: ACC synthase; ACT: Acyltransferase; AdoMet or SAM: Sadenosylmethionine; AP2: APETALA2; ARD: Acireductone dioxigenase;
AREF: Auxin response elements; ASP: Aspartate aminotransferase;

ATAF: ATAF-like NAC domain containing proteins; BBH: Best bidirectional hit; BRRE: Brassinosteroid response elements; CAAT: CCAAT binding factors; CBF: C repeat/interaction factor with DRE; CDC5: A. thaliana CDC5 homologs; CDPK (CPK): Calcium-dependent protein kinase; CE1F: Coupling elements 1 binding factors; ChIP: Chromatin immunoprecipitation; CNAC: Calcium regulated NAC-factors; CTR: Constitutive triple response; DEP: Dehydratase-enolase-phosphatase complex; DPBF: Dc3 promoter binding factors; DRE: Drought response element; DREB: Drought response element binding protein; GACC: 1-glutamyl-ACC; EAR: Ethylene responsive element binding factor associated with amphiphilic repression; EBF: EIN3 binding F-box protein; EIL: EIN3-like; EIN: Ethylene insensitive; EINL: EIN3-like factors; EOL: ETO-like; EREBEP: Ethylene responsive element binding protein; EREF: Ethylene response element factors; ERF: Ethylene response factor; ETO: Ethylene overproducer; ETP: EIN2 targeting protein; ETR: Ethylene receptor; FLO2: Floral homeotic protein APETALA2; GARP: MYB-related DNA binding proteins - Golden2, ARR, Psr; GBOX: plant G-box/C-box bZIP proteins; GCCF: GCC-box family; GO: Gene ontology; GT: $\gamma$-glutamyl transpeptidase; HEAT: Heat shock factors; JARE: Jasmonate response elements; LREM: Light responsive element motifs, not modulated by different light qualities; MACC: 1-malonyl-ACC; MIIG: MYB IIG-type binding sites; MKK: MAP kinase kinase; MKKK: MAP kinase kinase kinase; MPK: Mitogen-activated protein kinase; MTA: 5-methylthioadenosine; MTI: 5-methylthioribose-1-phosphate isomerase; MTK: 5-methylthioribose kinase; MTN: 5-methylthioadenosine nucleosidase; MYBL: MYB-like proteins; MYBS: MYB proteins with single DNA binding repeat; MYCL: MYC-like basic helix-loop-helix binding factors; NACF: Plant specific NAC transcriptional factors; PTBP: Plant TATA binding protein factors; SAMS (MAT): S-adenosylmethionine synthetase (methionine adenosyltransferase); RAN: Responsive to agonist; RAV: Related to ABI3NP1; RAV3: 3'-part of bipartite RAV1 binding site; RAV5: 5'-part of bipartite RAV1 binding site; RTE: Reversion to ethylene sensitivity; SALT: Salt/drought responsive elements; SSH: Subtraction library hybridization; SWNS: Secondary wall NACS; WUE: Water consumption.

\section{Competing interests}

The authors declare that they have no competing interests.

\section{Authors' contributions}

AFBM carried out all experiments and data analysis. BMA, LSME and AEVS helped in CDNA preparation and RT-GPCR experiments and PJFR contributed with in silico analyzes of possible promoters. MSRR performed greenhouse experiments and sampling. PE coordinated the experiments to determine levels of ethylene production and free ACC. GSMF and NAL conceived the study, planned the experiments, and helped draft the manuscript. All authors read and approved the final manuscript

\section{Acknowledgments}

This research was financially supported by grants from the Brazil Higher Education Personnel Training Coordination (CAPES), the Brazil National Council for Scientific and Technological Development (CNPq), the Brazilian Foundation for Research Support (FAP-DF) and Embrapa Genetic Resources and Biotechnology (Brazil).

\section{Author details}

${ }^{1}$ Federal University of Rio Grande do Sul, Campus do Vale, Av. Bento Gonçalves 9500, Postal Code 15005 CEP 91501-970, Porto Alegre, RS, Brazil. ${ }^{2}$ Embrapa Genetic Resources and Biotechnology, PaEB, Av. W5-Norte, Postal Code 02372, CEP 70770-910, Brasilia, DF, Brazil. " Brasilia University - Biology Institute, Brasilia, DF, Brazil. ${ }^{4}$ Agricultural Research Company of Minas Gerais State, Rua Afonso Rato 1301, Postal Code 311, CEP 38001-970, Uberaba, MG, Brazil. ${ }^{5}$ Embrapa Soybean, Rodovia Carlos João Strass, SN, Acesso Orlando Amaral, Distrito de Warta, Postal Code 231, CEP 86001-970, Londrina, PR, Brazil. ${ }^{6}$ Food Chemistry and Biochemistry Laboratory, Sao Paulo University, Av. Lineu Prestes 580, Bloco 14, Cidade Universitaria, CEP 05508-000, Sao Paulo, SP, Brazil. 'Catholic University of Brasilia, SGAN 916, Modulo B, Av. W5, Asa Norte, CEP 70790-160, Brasilia, DF, Brazil.

Received: 23 March 2015 Accepted: 20 August 2015

Published online: 03 September 2015 


\section{References}

1. Gerashchenkov GA, Rozhnova NA. The involvement of phytohormones in the plant sex regulation. Russ J Plant Physiol. 2013;60(5):597-610.

2. Forcat S, Bennett M, Mansfield J, Grant M. A rapid and robust method for simultaneously measuring changes in the phytohormones ABA, JA and SA in plants following biotic and abiotic stress. Plant Methods. 2008:4(1):16-23.

3. Bari R, Jones JDG. Role of plant hormones in plant defence responses. Plant Mol Biol. 2009;69(4):473-88

4. Kaya C, Tuna AL, Yokas I. The role of plant hormones in plants under salinity stress. In: Ashraf M, Ozturk M, Athar HR, editors. Salinity and Water Stress. vol. 44th ed. Netherlands: Springer; 2009. p. 45-50.

5. Santner A, Estelle M. The ubiquitin-proteasome system regulates plant hormone signaling. Plant J. 2010;61(6):1029-40.

6. Doubt SL. The response of plants to illuminating gas. Bot Gaz. 1917;63(3):209-24

7. Nath P, Trivedi PK, Sane VA, Sane AP. Role of ethylene in fruit ripening. In: Khan N, editor. Ethylene Action in Plants. Berlin Heidelberg: Springer; 2006. p. 151-84.

8. Trusov Y, Botella JR. Silencing of the ACC synthase gene ACACS2 causes delayed flowering in pineapple [Ananas comosus (L.) Merr.]. J Exp Bot. 2006:57(14):3953-60

9. Wilmowicz E, Kesy J, Kopcewicz J. Ethylene and ABA interactions in the regulation of flower induction in Pharbitis nil. J Plant Physiol. 2008;165(18):1917-28.

10. Yang SF, Hoffman NE. Ethylene biosynthesis and its regulation in higher plants. Annu Rev Plant Physiol. 1984;35(1):155-89.

11. Bleecker $A B$. Ethylene perception and signaling: An evolutionary perspective. Trends Plant Sci. 1999;4(7):269-74.

12. Miyazaki JH, Yang SF. Metabolism of 5-methylthioribose to methionine. Plant Physiol. 1987;84(2):277-81

13. Roje S. S-adenosyl-L-methionine: Beyond the universal methyl group donor. Phytochemistry. 2006;67(15):1686-98.

14. Argueso CT, Hansen M, Kieber JJ. Regulation of ethylene biosynthesis. J Plant Growth Regul. 2007;26(2):92-105.

15. Liang X, Abel S, Keller JA, Shen NF, Theologis A. The 1-aminocyclopropane-1-carboxylate synthase gene family of Arabidopsis thaliana. Proc Natl Acad Sci. 1992;89(22):11046-50.

16. Liang $X$, Oono $Y$, Shen NF, Köhler C, Li K, Scolnik PA, et al. Characterization of two members (ACS1 and ACS3) of the 1-aminocyclopropane-1-carboxylate synthase gene family of Arabidopsis thaliana. Gene. 1995;167(1-2):17-24.

17. Yamagami T, Tsuchisaka A, Yamada K, Haddon WF, Harden LA, Theologis A. Biochemical diversity among the 1-amino-cyclopropane-1-carboxylate synthase isozymesencoded by the Arabidopsis gene family. J Biol Chem. 2003:278(49):49102-12.

18. Liu Y, Zhang S. Phosphorylation of 1-aminocyclopropane-1-carboxylic acid synthase by MPK6, a stress-responsive mitogen-activated protein kinase, induces ethylene biosynthesis in Arabidopsis. Plant Cell. 2004;16(12):3386-99.

19. Tatsuki M, Mori H. Phosphorylation of tomato 1-aminocyclopropane-1carboxylic acid synthase, Le-ACS2, at the C-terminal region. J Biol Chem. 2001;276(30):28051-7.

20. Wang KLC, Yoshida H, Lurin C, Ecker JR. Regulation of ethylene gas biosynthesis by the Arabidopsis ETO1 protein. Nature 2004;428(6986):945-50.

21. Hahn A, Harter K. Mitogen-activated protein kinase cascades and ethylene: Signaling, biosynthesis, or both? Plant Physiol. 2009;149(3):1207-10.

22. Hegg EL, Que-Jr L. The 2-his-1-carboxylate facial triad — an emerging structural motif in mononuclear non-heme iron(II) enzymes. Eur J Biochem. 1997;250(3):625-9.

23. Hoffman NE, Yang SF, McKeon T. Identification of 1(malonylamino)cyclopropane-1-carboxylic acid as a major conjugate of 1-aminocyclopropane-1-carboxylic acid, an ethylene precursor in higher plants. Biochem Biophys Res Commun. 1982;104(2):765-70.

24. Amrhein N, Dorzok U, Kionka C, Kondziolka U, Skorupka H, Tophof S. The biochemistry and physiology of 1-aminocyclopropane-1-carboxylic acid conjugation. In: Fuchs Y, Chalutz E, editors. Ethylene. vol. 9th ed. Netherlands: Springer; 1984. p. 11-20.

25. Martin MN, Cohen JD, Saftner RA. A new 1-aminocyclopropane-1-carboxylic acid-conjugating activity in tomato fruit. Plant Physiol. 1995;109(3):917-26.

26. Glick BR. Modulation of plant ethylene levels by the bacterial enzyme ACC deaminase. FEMS Microbiol Lett. 2005;251(1):1-7.
27. Klee HJ, Hayford MB, Kretzmer KA, Barry GF, Kishore GM. Control of ethylene synthesis by expression of a bacterial enzyme in transgenic tomato plants. Plant Cell. 1991;3(11):1187-93.

28. Plett MJ, McDonnell L, Regan S. Plant encoded 1-aminocyclopropane1 -carboxylic acid deaminase activity implicated in different aspects of plant development. Plant Signal Behav. 2009;4(12):1186-9.

29. McDonnell L, Plett JM, Andersson-Gunneras S, Kozela C, Dugardeyn J, Van Der Straeten $D$, et al. Ethylene levels are regulated by a plant encoded 1-aminocyclopropane-1-carboxylic acid deaminase. Physiol Plant. 2009;136(1):94-109.

30. Qiao H, Chang KN, Yazaki J, Ecker JR. Interplay between ethylene, ETP1/ETP2 F-box proteins, and degradation of EIN2 triggers ethylene responses in Arabidopsis. Genes Dev. 2009;23(4):512-21.

31. Ju C, Yoon GM, Shemansky JM, Lin DY, Ying ZI, Chang J, et al. CTR1 phosphorylates the central regulator EIN2 to control ethylene hormone signaling from the ER membrane to the nucleus in Arabidopsis. Proc Natl Acad Sci. 2012;109(47):19486-91.

32. Yoo S-D, Cho Y-H, Tena G, Xiong Y, Sheen J. Dual control of nuclear EIN3 by bifurcate MAPK cascades in $\mathrm{C}_{2} \mathrm{H}_{4}$ signalling. Nature. 2008;451(7180):789-95.

33. Stepanova AN, Alonso JM. Ethylene signaling and response: Where different regulatory modules meet. Curr Opin Plant Biol. 2009;12(5):548-55.

34. Olmedo G, Guo H, Gregory BD, Nourizadeh SD, Aguilar-Henonin L, Li H, et al. Ethylene-insensitive 5 encodes a $5^{\prime} \rightarrow 3^{\prime}$ exoribonuclease required for regulation of the EIN3-targeting F-box proteins EBF1/2. Proc Natl Acad Sci. 2006;103(36):13286-93.

35. Ohme-Takagi M, Shinshi $\mathrm{H}$. Ethylene-inducible DNA binding proteins that interact with an ethylene-responsive element. Plant Cell. 1995;7(2):173-82.

36. Deikman J, Xu R, Kneissl ML, Ciardi JA, Kim K-N, Pelah D. Separation of cis-elements responsive to ethylene, fruit development, and ripening in the 5 '-flanking region of the ripening-related E8 gene. Plant Mol Biol. 1998;37(6):1001-11.

37. Leubner-Metzger G, Petruzzelli L, Waldvogel R, Vogeli-Lange R, Meins Jr F. Ethylene-responsive element binding protein (EREBP) expression and the transcriptional regulation of class I $\beta$-1,3-glucanase during tobacco seed germination. Plant Mol Biol. 1998;38(5):785-95.

38. Solano R, Stepanova A, Chao Q, Ecker JR. Nuclear events in ethylene signaling: A transcriptional cascade mediated by ethylene-insensitive 3 and ethylene-response-factor 1. Genes Dev. 1998;12(23):3703-14.

39. Vandenbussche F, Vaseva I, Vissenberg K, Van Der Straeten D. Ethylene in vegetative development: A tale with a riddle. New Phytol. 2012;194(4):895-909.

40. Ding Y, Virlouvet L, Liu N, Riethoven J-J, Fromm M, Avramova Z. Dehydration stress memory genes of Zea mays: Comparison with Arabidopsis thaliana. BMC Plant Biol. 2014;14(1):141.

41. Shinozaki K, Yamaguchi-Shinozaki K. Gene networks involved in drought stress response and tolerance. J Exp Bot. 2007;58(2):221-7.

42. Guimaraes-Dias F, Neves-Borges AC, Viana AAB, Mesquita RO, Romano E, Grossi-de-Sa MF, et al. Expression analysis in response to drought stress in soybean: Shedding light on the regulation of metabolic pathway genes. Genet Mol Biol. 2012;35:222-32.

43. Yamaguchi-Shinozaki K, Shinozaki K. A novel cis-acting element in an Arabidopsis gene is involved in responsiveness to drought, low-temperature, or high-salt stress. Plant Cell. 1994;6(2):251-64.

44. Kizis D, Pages M. Maize DRE-binding proteins DBF1 and DBF2 are involved in rab17 regulation through the drought-responsive element in an ABA-dependent pathway. Plant J. 2002;30(6):679-89.

45. Wilkinson S, Kudoyarova GR, Veselov DS, Arkhipova TN, Davies WJ. Plant hormone interactions: Innovative targets for crop breeding and management. J Exp Bot. 2012;63(9):3499-509.

46. Aeong Oh S, Park J-H, In Lee G, Hee Paek K, Ki Park S, Gil Nam H. Identification of three genetic loci controlling leaf senescence in Arabidopsis thaliana. Plant J. 1997;12(3):527-35.

47. Voesenek $L A C J$, Bailey-Serres J. Plant biology: Genetics of high-rise rice. Nature. 2009:460(7258):959-60.

48. Habben JE, Bao X, Bate NJ, DeBruin JL, Dolan D, Hasegawa D, et al. Transgenic alteration of ethylene biosynthesis increases grain yield in maize under field drought-stress conditions. Plant Biotechnol J. 2014;12(6):685-93.

49. Fujimoto SY, Ohta M, Usui A, Shinshi H, Ohme-Takagi M. Arabidopsis ethylene-responsive element binding factors act as transcriptional activators or repressors of GCC Box-mediated gene expression. Plant Cell Online. 2000;12(3):393-404. 
50. Xu Z-S, Xia L-Q, Chen M, Cheng X-G, Zhang R-Y, Li L-C, et al. Isolation and molecular characterization of the Triticum aestivum $L$. ethylene-responsive factor 1 (TaERF1) that increases multiple stress tolerance. Plant Mol Biol. 2007:65(6):719-32

51. Global consumption of vegetable oils from $1995 / 1996$ to $2013 / 2014$, by oil type (in million metric tons). Available in:<http://www.statista.com/statistics/ 263937/vegetable-oils-global-consumption/>. Accessed in: (08/18/2014). [http://www.statista.com/statistics/263937/vegetable-oils-globalconsumption]

52. USDA. Soybeans \& oil crops. 2014. Available in: <http://www.ers.usda.gov/topics/ crops/soybeans-oil-crops.aspx\#.U_I2CGOgxnG>. Accessed in: (08/18/2014).

53. Pommerrenig B, Feussner K, Zierer W, Rabinovych V, Klebl F, Feussner I, et al. Phloem-specific expression of Yang cycle genes and identification of novel Yang cycle enzymes in Plantago and Arabidopsis. Plant Cell. 2011;23(5):1904-19.

54. Amthor JS. Efficiency of lignin biosynthesis: A quantitative analysis. Ann Bot. 2003;91(6):673-95.

55. Tucker ML, Xue P, Yang R. 1-aminocyclopropane-1-carboxylic acid (ACC) concentration and ACC synthase expression in soybean roots, root tips, and soybean cyst nematode (Heterodera glycines)-infected roots. J Exp Bot. 2010;61(2):463-72

56. Kende H. Ethylene biosynthesis. Annu Rev Plant Physiol Plant Mol Biol. 1993:44(1):283-307.

57. Chang C, Kwok SF, Bleecker AB, Meyerowitz EM. Arabidopsis ethylene-response gene ETR1: Similarity of product to two-component regulators. Science. 1993;262(5133):539-44.

58. Hua J, Chang C, Sun Q, Meyerowitz EM. Ethylene insensitivity conferred by Arabidopsis ERS gene. Science. 1995;269(5231):1712-4.

59. Hua J, Meyerowitz EM. Ethylene responses are negatively regulated by a receptor gene family in Arabidopsis thaliana. Cell. 1998;94(2):261-71.

60. Sakai H, Hua J, Chen QG, Chang C, Medrano LJ, Bleecker AB, et al. ETR2 is an ETR1-like gene involved in ethylene signaling in Arabidopsis. Proc Natl Acad Sci. 1998;95(10):5812-7.

61. Wittkopp PJ, Kalay G. cis-regulatory elements: Molecular mechanisms and evolutionary processes underlying divergence. Nat Rev Genet. 2012;13(1):59-69.

62. Cheng M-C, Liao P-M, Kuo W-W, Lin T-P. The Arabidopsis ethylene response factor 1 regulates abiotic stress-responsive gene expression by binding to different cis-acting elements in response to different stress signals. Plant Physiol. 2013;162(3):1566-82.

63. Vandenbussche F, Vriezen WH, Smalle J, Laarhoven LJJ, Harren FJM, Van Der Straeten D. Ethylene and auxin control the Arabidopsis response to decreased light intensity. Plant Physiol. 2003;133(2):517-27.

64. Bours R, Van Zanten M, Pierik R, Bouwmeester H, Van Der Krol A. Antiphase light and temperature cycles affect phytochrome B-controlled ethylene sensitivity and biosynthesis, limiting leaf movement and growth of Arabidopsis. Plant Physiol. 2013;163(2):882-95.

65. Steed CL, Taylor LK, Harrison MA. Red light regulation of ethylene biosynthesis and gravitropism in etiolated pea stems. Plant Growth Regul. 2004:43(2):117-25.

66. Thain SC, Vandenbussche F, Laarhoven LJJ, Dowson-Day MJ, Wang Z-Y, Tobin EM, et al. Circadian rhythms of ethylene emission in Arabidopsis. Plant Physiol. 2004;136(3):3751-61.

67. An F, Zhao Q, Ji Y, Li W, Jiang Z, Yu X et al. Ethylene-induced stabilization of ethylene insensitive 3 and EIN3-like 1 is mediated by proteasomal degradation of EIN3 binding F-box 1 and 2 that requires EIN2 in Arabidopsis. Plant Cell. 2010;22(7):2384-401.

68. Jiao Y, Lau OS, Deng XW. Light-regulated transcriptional networks in higher plants. Nat Rev Genet. 2007;8(3):217-30.

69. Alcazar R, Altabella T, Marco F, Bortolotti C, Reymond M, Koncz C, et al. Polyamines: Molecules with regulatory functions in plant abiotic stress tolerance. Planta. 2010;231(6):1237-49.

70. Espartero J, Pintor-Toro JA, Pardo JM. Differential accumulation of S-adenosylmethionine synthetase transcripts in response to salt stress. Plant Mol Biol. 1994;25(2):217-27.

71. Zhang G, Chen M, Li L, Xu Z, Chen X, Guo J, et al. Overexpression of the soybean GmERF3 gene, an AP2/ERF type transcription factor for increased tolerances to salt, drought, and diseases in transgenic tobacco. J Exp Bot. 2009;60(13):3781-96

72. Abel S, Theologis A. Early genes and auxin action. Plant Physiol. 1996;111(1):9-17.
73. Lim SH, Chang SC, Lee JS, Kim S-K, Kim SY. Brassinosteroids affect ethylene production in the primary roots of maize (Zea mays L.). J Plant Biol. 2002;45(3):148-53.

74. Sanz LC, Fernandez-Maculet JC, Gomez E, Vioque B, Olias JM. Effect of methyl jasmonate on ethylene biosynthesis and stomatal closure in olive leaves. Phytochemistry. 1993;33(2):285-9.

75. Rodrigues FA, Marcolino-Gomes J, Carvalho JFC, Nascimento LC, Neumaier N, Farias JRB, et al. Subtractive libraries for prospecting differentially expressed genes in the soybean under water deficit. Genet Mol Biol. 2012;35:304-14.

76. Jiao X-Z, Philosoph-Hadas S, Su L-Y, Yang SF. The conversion of 1(malonylamino)cyclopropane-1-carboxylic acid to 1-aminocyclopropane1-carboxylic acid in plant tissues. Plant Physiol. 1986;81(2):637-41.

77. Fluhr R, Mattoo AK, Dilley DR. Ethylene - biosynthesis and perception. Crit Rev Plant Sci. 1996:15(5-6):479-523.

78. Chen LIN, Dodd IC, Davies WJ, Wilkinson S. Ethylene limits abscisic acid- or soil drying-induced stomatal closure in aged wheat leaves. Plant Cell Environ. 2013;36(10):1850-9.

79. Spollen WG, LeNoble ME, Samuels TD, Bernstein N, Sharp RE. Abscisic acid accumulation maintains maize primary root elongation at low water potentials by restricting ethylene production. Plant Physiol. 2000;122(3):967-76.

80. Sharp RE. Interaction with ethylene: Changing views on the role of abscisic acid in root and shoot growth responses to water stress. Plant Cell Environ. 2002;25(2):211-22.

81. Bailey-Serres J, Voesenek LACJ. Flooding stress: Acclimations and genetic diversity. Annu Rev Plant Biol. 2008;59(1):313-39.

82. Antunes MDC, Sfakiotakis EM. Effect of high temperature stress on ethylene biosynthesis, respiration and ripening of 'Hayward' kiwifruit. Postharvest Biology Technol. 2000;20(3):251-9.

83. Swarbreck D, Wilks C, Lamesch P, Berardini TZ, Garcia-Hernandez M, Foerster $\mathrm{H}$, et al. The Arabidopsis information resource (TAIR): Gene structure and function annotation. Nucleic Acids Res. 2008;36 suppl 1:D1009-14.

84. Altschul SF, Gish W, Miller W, Myers EW, Lipman DJ. Basic local alignment search tool. J Mol Biol. 1990;215(3):403-10.

85. Nascimento LC, Costa GGL, Binneck E, Pereira GAG, Carazzolle MF. A web-based bioinformatics interface applied to the GENOSOJA project: Databases and pipelines. Genet Mol Biol. 2012;35:203-11.

86. Kawahara Y, de la Bastide M, Hamilton JP, Kanamori H, McCombie WR, Ouyang S, et al. Improvement of the Oryza sativa Nipponbare reference genome using next generation sequence and optical map data. Rice. 2013;6(1):1-10

87. Conesa A, Gotz S, García-Gomez JM, Terol J, Talon M, Robles M. Blast2GO: A universal tool for annotation, visualization and analysis in functional genomics research. Bioinformatics (Oxford, England). 2005;21(18):3674-6.

88. Jones $\mathrm{P}$, Binns $\mathrm{D}$, Chang H-Y, Fraser M, Li W, McAnulla $\mathrm{C}$, et al. InterProScan 5: Genome-scale protein function classification. Bioinformatics (Oxford, England). 2014;30(9):1236-40.

89. Ashburner M, Ball CA, Blake JA, Botstein D, Butler H, Cherry JM, et al. Gene ontology: Tool for the unification of biology. Nat Genet. 2000;25(1):25-9.

90. Punta M, Coggill PC, Eberhardt RY, Mistry J, Tate J, Boursnell C, et al. The PFAM protein families database. Nucleic Acids Res. 2012;40(D1):D290-301.

91. Schmutz J, Cannon SB, Schlueter J, Ma J, Mitros T, Nelson W, et al. Genome sequence of the palaeopolyploid soybean. Nature. 2010;463(7278):178-83.

92. Selkov E, Grechkin Y, Mikhailova N. MPW: The metabolic pathways database. Nucleic Acids Res. 1998;26(1):43-5.

93. Kanehisa M, Goto S. KEGG: Kyoto encyclopedia of genes and genomes. Nucleic Acids Res. 2000;28(1):27-30.

94. Blom N, Gammeltoft S, Brunak S. Sequence and structure-based prediction of eukaryotic protein phosphorylation sites. J Mol Biol. 1999;294(5):1351-62

95. Dalquen DA, Dessimoz C. Bidirectional best hits miss many orthologs in duplication-rich clades such as plants and animals. Genome Biol Evol. 2013;5(10):1800-6

96. Cartharius K, Frech K, Grote K, Klocke B, Haltmeier M, Klingenhoff A, et al. MatInspector and beyond: Promoter analysis based on transcription factor binding sites. Bioinformatics (Oxford, England). 2005;21(13):2933-42.

97. Casagrande EC, Farias JRB, Neumaier N, Oya T, Pedroso J, Martins PK, et al, Expressão gênica diferencial durante déficit hídrico em soja. Rev Bras Fisiol Veg. 2001;13:168-84

98. Texeira LR, Braccini AL, Sperandio D, Scapim CA, Schuster I, Vigano J. Avaliação de cultivares de soja quanto à tolerância ao estresse hídrico em substrato contendo polietileno glicol, vol. 30. 2008. 
99. Hoagland DR, Arnon DI. The water-culture method for growing plants without soil: University of California. 1938.

100. Fehr WR, Caviness CE, Burmood DT, Pennington JS. Stage of development descriptions for soybeans, Glycine Max (L.) Merrill. Crop Sci. 1971;11(6):929-31.

101. Untergasser A, Nijveen H, Rao X, Bisseling T, Geurts R, Leunissen JAM. Primer3Plus, an enhanced web interface to Primer3. Nucleic Acids Res. 2007;35 suppl 2:W71-4.

102. Kulcheski FR, Marcelino-Guimaraes FC, Nepomuceno AL, Abdelnoor RV, Margis R. The use of microRNAs as reference genes for quantitative polymerase chain reaction in soybean. Anal Biochem. 2010;406(2):185-92.

103. Miranda VJ, Coelho RR, Viana AA, de Oliveira Neto OB, Carneiro RM, Rocha $T L$, et al. Validation of reference genes aiming accurate normalization of qPCR data in soybean upon nematode parasitism and insect attack. BMC Res Notes. 2013;6:196-205.

104. Zhao S, Fernald RD. Comprehensive algorithm for quantitative real-time polymerase chain reaction. J Comput Biol. 2005;12(8):1047-64.

105. Hellemans J, Mortier G, De Paepe A, Speleman F, Vandesompele J. qBase relative quantification framework and software for management and automated analysis of real-time quantitative PCR data. Genome Biol. 2007:8(2):R19.

106. Pfaffl MW, Horgan GW, Dempfle L. Relative expression software tool (RESTC) for group-wise comparison and statistical analysis of relative expression results in real-time PCR. Nucleic Acids Res. 2002;30(9):e36-45.

107. Mainardi JA, Purgatto E, Vieira AJ, Bastos WA, Cordenunsi BR, Nascimento JR $\mathrm{O} d$, et al. Effects of ethylene and 1-methylcyclopropene (1-MCP) on gene expression and activity profile of a-1,4-glucan-phosphorylase during banana ripening. J Agric Food Chem. 2006;54(19):7294-9.

108. Liu M, Zhu S, Zhou J. Determination of 1-aminocyclopropane-1-carboxylic acid in apple and peach extracts by high performance liquid chromatography coupled to a fluorescence detector. Anal Lett. 2012;45(16):2324-33.

109. Ecker JR. Reentry of the ethylene MPK6 module. Plant Cell. 2004;16(12):3169-73.

110. Binder BM, Rodriguez Fl, Bleecker AB. The copper transporter responsive-toantagonist 1 (RAN1) is essential for the biogenesis of ethylene receptors in Arabidopsis. J Biol Chem. 2010.

111. Dong C-H, Rivarola M, Resnick JS, Maggin BD, Chang C. Subcellular co-localization of Arabidopsis RTE1 and ETR1 supports a regulatory role for RTE1 in ETR1 ethylene signaling. Plant J. 2008;53(2):275-86.

\section{Submit your next manuscript to BioMed Central and take full advantage of:}

- Convenient online submission

- Thorough peer review

- No space constraints or color figure charges

- Immediate publication on acceptance

- Inclusion in PubMed, CAS, Scopus and Google Scholar

- Research which is freely available for redistribution 